\author{
UNIVERSIDADE DE SÃO PAULO \\ FACULDADE DE CIÊNCIAS FARMACÊUTICAS \\ Programa de Pós-graduação em Tecnologia Bioquimico- \\ Farmacêutica \\ Área de Tecnologia Químico-Farmacêutica
}

\title{
PROPOSIÇÃO DE NOVA ROTA DE SÍNTESE DO MEGAZOL
}

Cecilia Rodrigues de Silva Amaro

Dissertação para obtenção do grau de Mestre

Orientadora:

Professora Dra Cristina N.Albuquerque

São Paulo

2003 
Cecilia Rodrigues de Silva Amaro

PROPOSTA DE NOVA ROTA DE SÍNTESE DO MEGAZOL

\author{
Comissão Julgadora \\ da
}

Dissertação para obtenção do grau de Mestre

Profa. Dra. Cristina Northfleet de Albuquerque

Orientador/presidente

$1^{\circ}$ Examinador

$2^{\circ}$ Examinador

São Paulo, de 


\section{AGRADECIMENTOS}

À professora Dra. Cristina N. Albuquerque, pelo apoio e dedicação na orientação deste trabalho, sempre disponível e empenhada em ajudar-me em todos os momentos que necessitei.

À professora Dra. Dominique C. H. Fischer pelo apoio e valiosa colaboração e sugestões no decorrer das sínteses, pela colaboração na aquisição de reagentes e também pela participação na banca de qualificação, na qual contribuiu com importantes idéias para a execução deste trabalho.

À professora Dra. Suzana C. S. Lannes, pela participação na banca de qualificação, na qual sua contribuição foi de grande valia para a elaboração deste trabalho.

Ao professor Dr. Bronislaw Polakiewicz, pelo apoio e incentivo, e também por compartilhar equipamentos e reagentes de seu laboratório.

Ao professor Dr. José Abrahão, pelo empréstimo de reagentes.

Aos meus colegas de laboratório, André L. S. Novaes, Renata P. Borges, Karla T. F. de Novaes, Carla Ap. Pedriali, Karine Gargioni, e especialmente ao Marcos C. Knirsch, por toda ajuda na elaboração deste trabalho.

Ao Juarez, Miriam, Elza, Jorge e Elaine, pela gentileza com que tratam os alunos e fornecem as informações necessárias.

Aos meus pais, João da Silva Amaro e Florinda Rodrigues, sem os quais eu jamais teria chegado neste momento tão importante de minha vida.

Em fim, a todas as pessoas que colaboraram direta ou indiretamente para a realização desse trabalho. 


\section{SUMÁRIO}

$\begin{array}{ll}\text { RESUMO } & 06\end{array}$

$\begin{array}{ll}\text { ABSTRACT } & 07\end{array}$

1.INTRODUÇÃO 08

2.REVISÃO BIBLIOGRÁFICA

2.1.Química dos compostos heterocíclicos 13

2.2. A Doença de Chagas 20

2.2.1.Terapêutica Experimental da doença de Chagas 23

2.2.1.1.Nifurtimox (13) e benzonidazol (14) 24

2.3.Megazol (12) 26

2.4.Rotas de obtenção do megazol (12) 29

3.OBJETIVO 37

4.MATERIAIS E MÉTODOS 39

4.1.Materiais 39

4.1.1.Solventes $\quad 39$

4.1.2.Reagentes $\quad 39$

4.1.3.Equipamentos $\quad 39$

4.2. Métodos $\quad 40$

4.2.1.Primeira etapa - Cianação 40

4.2.2. Segunda etapa - Ciclização 41

4.2.3. Terceira etapa - Nitração 42

5.PROPOSIÇÃO DE NOVA ROTA DE SÍNTESE

5.1.Cianação 43

5.2.Ciclização 45

5.3.Nitração 47

6.RESULTADOS E DISCUSSÃO 49

6.1.Execução da Cianação $\quad 49$

6.2. Execução da Ciclização 49

6.3.Execução da Nitração 50

7.CONCLUSÕES E PERSPECTIVAS

8.BIBLIOGRAFIA $\quad 54$

9.ANEXOS 60 
RELAÇÃO DE FIGURAS E TABELAS

FIGURAS:

Figura 1: Estrutura da nitrofurazona (1) 08

Figura 2: Estrutura do 2-nitroimidazol (2) 09

Figura 3: Fármacos com atividade tripanossomicida 09

Figura 4: Estrutura do metronidazol (5) 10

Figura 5: Estrutura do megazol (12) 12

Figura 6: Estruturas do benzeno 14

Figura 7: Estrutura da piridina $\quad 15$

Figura 8: Estrutura do pirrol 16

Figura 9: Formas canônicas do imidazol 17

Figura 10: Equilíbrio tautomérico do 4(5)-metilimidazol 19

Figura 11: Formação do anel imidazólico 19

Figura 12: Esquema das principais reações do anel imidazólico 20

Figura 13: Fármacos com atividade antichagásica $\quad 24$

Figura 14: Estrutura do ácido nalidíxico (15) 28

Figura 15: Esquema de síntese do megazol (12), descrito por Berkelhammer e Asato, em $1968 \quad 29$

Figura 16: Esquema de síntese do megazol (12), proposto por Remers, Gibs e Weiss, em $1969 \quad 31$

Figura 17: Esquema de síntese do megazol (12), proposto por Albright e Shephard, em $1973 \quad 32$

Figura 18: Rota de síntese proposta para obtenção do megazol (12), proposto por Albuquerque e col., em 1995

Figura 19: Rota de síntese do megazol (12), otimizada por Moretto, em 2001

Figura 20: Esquema da nova rota para sintese do megazol (12) 38

Figura 21: Formação do C.A.P. 43

Figura 22: Mecanismo proposto para a cianação do 1-metilimidazol (16), via C.A.P. $\quad 44$

Figura 23: Proposição para o mecanismo de ciclização 46

Figura 24: Esquema de nitração 48

TABELAS:

Tabela 1:Principais fármacos do tipo 5-nitroimidazol 11 


\section{RESUMO}

Em 1968, um composto do tipo 5-nitroimidazol, o megazol, foi sintetizado por Berkelhammer e Asato e demonstrou largo espectro de ação biológica.

Em 1980, pesquisadores brasileiros determinaram excelente atividade desta molécula contra o Tripanosoma cruzi, em ratos, por via oral.

Constam da literatura quatro rotas para a obtenção deste fármaco, que podem ser otimizadas no tocante ao aumento da produtividade e minimização dos riscos.

A nova rota, ora proposta, é uma alternativa para a síntese do megazol, realizada somente em três etapas de fácil execução, abrindo caminho para obtenção de seus análogos estruturais. 


\section{ABSTRACT}

In 1968, Berkelhammer and Asato synthesized a compound of the 5-nitroimidazole group, called megazol. This compound demonstrated a high biological activity.

In 1980 , brazilian researchers tested the megazol in mices and they discovered an excellent activity of this against Chagas' disease.

There are four routes to synthesize these compound indicated in the literature. Actually, these routes can be optimized to achieve the yield and minimization of the risks involved in the unitary process.

The new route proposed is an alternative to obtain the megazol in only three stages of easy perform. This method makes way to structural analogues of this drug. 


\section{INTRODUÇÃO}

Os nitroimidazóis pertencem a um grupo de compostos nitroeterocíclicos que desempenham um importante papel em quimioterapia. O primeiro composto deste grupo utilizado com fins terapêuticos foi a nitrofurazona (1), que é um derivado do nitrofurano (BRECCIA, CAVALLERI, ADAMS, 1982). A atividade antibacteriana da nitrofurazona (1) despertou o interesse no estudo e no uso de compostos heterocíclicos, sendo que os nitroimidazóis ganharam destaque uma vez que apresentam atividade antiparasitária (BRENER, ANDRADE, BARRAL-NETTO, 2000).<smiles>NC(=O)N/N=C/c1ccc([N+](=O)[O-])o1</smiles>

Figura 1: Estrutura da nitrofurazona (1)

Os nitroimidazóis apresentam atividade contra tricomonas, amebas, giárdias, histomonas e também algumas bactérias, porém este trabalho se interessa especialmente pela atividade contra $o$ Trypanosoma cruzi, parasita causador da doença de Chagas (CHAUVIĖRE, BOUTEILLE, ENANGA, ALBUQUERQUE, CROFT, DUMAS, PERIÉ, 2003).

O primeiro nitroimidazol utilizado como agente antiparasitário foi a azomicina (2) (2-nitroimidazol), em 1956, que foi produzido por processo fermentativo a partir de uma cepa de Streptomyces e cepas de Nocardia (NAIR, NAGARAJAN, 1983). A primeira patente sobre nitração de imidazóis foi registrada em 1957 
(JACOB, REGNIER, CRISAN, 1961). Desde então houve um grande desenvolvimento de métodos de síntese de imidazóis nitrados nas posições 2, 4 e 5. Dinitroimidazóis e halogenonitroimidazóis têm sido muito estudados devido ao seu potencial como radiossensibilizadores (BRECCIA, CAVALLERI, ADAMS, 1982). Várias pesquisas resultaram na descoberta de que o grupo dos 5-nitroimidazóis era mais ativo que seus isômeros 2 e 4 .<smiles>O=[N+]([O-])c1ncc[nH]1</smiles>

Figura 2: Estrutura do 2-nitroimidazol (2)

Para que haja atividade biológica é necessário que os 5nitroimidazóis estejam substituídos por grupos alquila na posição 1 . O modo de ação desses fármacos parece estar relacionado com a inibição de enzimas glicolíticas, com conseqüente morte do microorganismo devido a falta de energia. Também se sabe que os processos de oxidorredução celulares são influenciados pela presença de compostos nitrados.

Embora alguns desses compostos tenham mostrado atividade contra a tripanossomíase, como por exemplo, o flunidazol (3) e o ronidazol (4), os 5-nitroimidazóis ainda não são utilizados, no presente momento, com esta finalidade.<smiles>CCn1c([N+](=O)[O-])cnc1-c1ccc(F)cc1</smiles>

flunidazol (3)<smiles>Cn1c([N+](=O)[O-])cnc1COC(N)=O</smiles>

ronidazol (4)

Figura 3: Fármacos com atividade tripanossomicida. 
Dentre os 5-nitroimidazóis, o mais estudado do ponto de vista farmacocinético, é o metronidazol (5) Esta molécula constitui uma opção terapêutica para infecções provocadas por amebas, tricomonas e giárdias, devido a sua efetividade, curta duração das terapias e baixa toxicidade quando comparada com outros fármacos. Além disso, tem chamado atenção por sua ação contra bactérias anaeróbias e por seu potencial como radiossensibilizador. Os efeitos tóxicos produzidos pelo metronidazol (5) têm servido de guia para o estudo da toxicidade dessa classe de compostos. Os efeitos colaterais mais comuns envolvem os tratos gastrintestinais, geniturinários e o sistema nervoso central. Esse fármaco pode ainda causar discrasia sanguínea. Não há efeitos colaterais relacionados aos sistemas cardiovascular e respiratório. Merece atenção ainda, o estudo dos efeitos carcinogênicos da utilização de 5-nitroimidazóis. O potencial mutagênico dessa categoria de compostos já está confirmado a partir de estudos com o metronidazol (5). No entanto, cada novo fármaco deve ser avaliado comparando-se com padrões conhecidos. (MEO et al, 1992; BRECCIA, CAVALLERI, ADAMS, 1982).<smiles>Cc1ncc([N+](=O)[O-])n1CCO</smiles>

Figura 4: Estrutura do metronidazol (5)

A tabela a seguir contém um resumo dos principais 5nitroimidazóis que possuem atividade antiparasitária em uso e/ou em estudo atualmente (NAIR, NAGARAJAN, 1983). 
Tabela I: Principais fármacos do tipo 5-nitroimidazóis

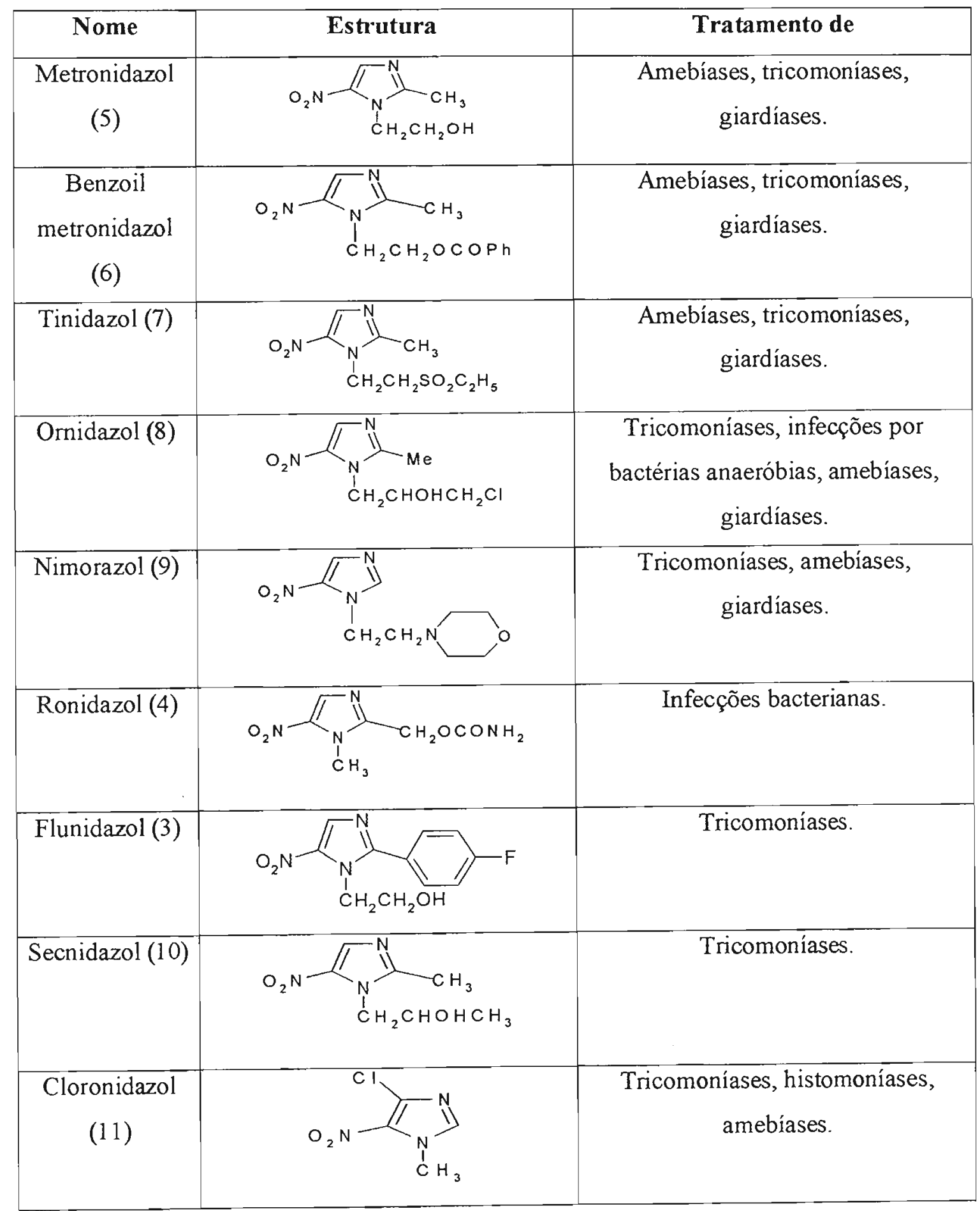


Este trabalho tem como foco a síntese de um fármaco com propriedades antichagásicas do grupo dos 5-nitroimidazóis, conhecido como megazol (12). Serão descritas, além dos principais aspectos químicos envolvendo os imidazóis, que serviram de base para a proposta da nova rota de síntese, algumas das principais características desta parasitose.

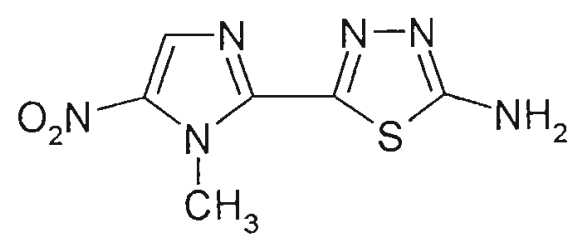

Figura 5: Estrutura do megazol (12) 


\section{REVISÃO BIBLIOGRÁFICA}

\subsection{Química dos Compostos Heterocíclicos}

Um grande número de compostos orgânicos como produtos naturais, fármacos ou compostos de interesse teórico são heterocíclicos. Estas estruturas desempenham também um importante papel em muitos processos biológicos. Compostos como o DNA, cocaína, nicotina, quinina, emetina, paraquat, antibióticos como a penicilina, e até uma grande variedade de vitaminas, também fazem parte dessa categoria de compostos.

Os heterocíclicos podem dividir-se em dois grupos principais: alifáticos e aromáticos. Os alifáticos são os análogos cíclicos de aminas, éteres, amidas etc, não apresentando ligações duplas ou triplas conjugadas em sua estrutura. Estes compostos possuem muitas propriedades em comum com seus correspondentes análogos acíclicos. Os aromáticos são compostos que possuem ligações duplas conjugadas, tendo heteroátomos no anel, possuindo algumas das propriedades típicas da química do benzeno.

O termo aromático surgiu em princípio como conseqüência do agradável odor que possuíam certos compostos, entre os quais vários óleos essenciais. Com o desenvolvimento de métodos precisos de análise por combustão, os compostos aromáticos se identificaram por possuírem uma proporção $\mathrm{H}: \mathrm{C}$ relativamente baixa, e se considerou o benzeno como o composto aromático modelo. 
Ao desenvolver-se a teoria estrutural ficou evidente que estes compostos ocupavam uma posição singular, pois ainda que fossem insaturados, eram relativamente inertes, sem manifestarem nenhuma das reações clássicas das olefinas. Por outro lado, ainda que a estrutura $A$ fosse a melhor descrição do benzeno mediante a teoria clássica, não foi possível isolar dois isômeros benzênicos ortosubstituídos tais como $B$ e $C$.<smiles>c1ccccc1</smiles>

$A$<smiles>[X]c1ccccc1[X]</smiles>

B<smiles>[X]c1ccccc1[X]</smiles>

C

Figura 6: Estruturas do benzeno.

A incapacidade da teoria clássica de ligações para descrever a estrutura do benzeno foi posteriormente solucionada ao considerar que nem $B$ ou $C$ representavam a estrutura real, a qual é um híbrido em que $B$ e $C$ têm contribuição. Nessa teoria conhecida como teoria da ressonância, as aproximações $B$ e $C$, denominam-se formas canônicas e são meras aproximações teóricas que não representam de modo algum a estrutura real.

No benzeno, ambas as formas canônicas devem contribuir em igual medida à estrutura híbrida real, de maneira que qualquer ligação seja uma média entre a ligação simples e a dupla. Baseando-se nessa teoria, acredita-se que o fato das ligações do benzeno serem intermediárias confere a estrutura maior estabilidade, denominando 
energia de ressonância à diferença entre a energia da ligação real do benzeno e a que teria a molécula teórica de cicloexatrieno. Isto indica que os elétrons $\pi$ não estão localizados em ligações olefinicas e a deslocalização confere estabilidade ao benzeno.

Os cálculos de Huckel estabelecem que qualquer sistema cíclico plano e totalmente conjugado está estabilizado por deslocalização se tem um total de $(4 n+2)$ elétrons $\pi$, sendo $n$ zero ou qualquer valor inteiro, enquanto que um sistema análogo com $4 n$ elétrons $\pi$ está desestabilizado por deslocalização. Então sistemas $(4 n+2)$ elétrons $\pi$ são aromáticos e sistemas $4 n$ elétrons $\pi$, não aromáticos. Os compostos da série $(4 n+2)$ elétrons $\pi$ têm propriedades similares ao benzeno.

Os heterocíclicos aromáticos podem ser considerados de dois tipos. O primeiro deriva de uma simples substituição de um carbono do anel aromático por um heteroátomo, como por exemplo, a piridina.<smiles>c1ccncc1</smiles>

Figura 7: Estrutura da piridina.

Esses compostos são aromáticos por terem $(4 n+2)$ elétrons $\pi$ deslocalizados sobre $(4 n+2)$ átomos, similares ao benzeno. Entretanto o sistema benzênico resulta perturbado ao substituir o carbono pelo átomo eletronegativo, já que esta eletronegatividade dará 
lugar a uma localização de densidade eletrônica sobre o(s) heteroátomo(s), originando uma perda de densidade eletrônica dos átomos de carbono. A química desses compostos está afetada pela polarização provocada por esta substituição. Estes sistemas são denominados $\pi$-deficientes devido à insuficiência eletrônica dos átomos de carbono do anel.

O segundo grupo de heterocíclicos aromáticos derivam da substituição de ligações $\mathrm{C}=\mathrm{C}$ por heteroátomos, como o pirrol. Trata-se agora de $(4 n+2)$ elétrons $\pi$ deslocalizados sobre $(4 n+1)$ átomos ou menos. Estes compostos são denominados $\pi$-excedentes.<smiles>c1cc[nH]c1</smiles>

Figura 8: Estrutura do pirrol.

Alguns heterocíclicos aromáticos podem ser considerados como sistemas mistos por mostrar em seu comportamento características de compostos $\pi$-deficientes e de $\pi$-excedentes, onde um dos átomos de nitrogênio substitui o carbono, como a piridina, ou de outros sistemas $\pi$-deficientes, e o outro substitui a ligação $C=C$, como o pirrol, que é $\pi$-excedente.

Os imidazóis podem ser considerados derivados do benzeno contendo um átomo de nitrogênio pirrólico e um piridínico, nas 
posições 1 e 3 , respectivamente. A química desses compostos mostra, portanto, similaridades com a piridina e com o pirrol.

Os imidazóis podem ser representados pelas seguintes formas canônicas:

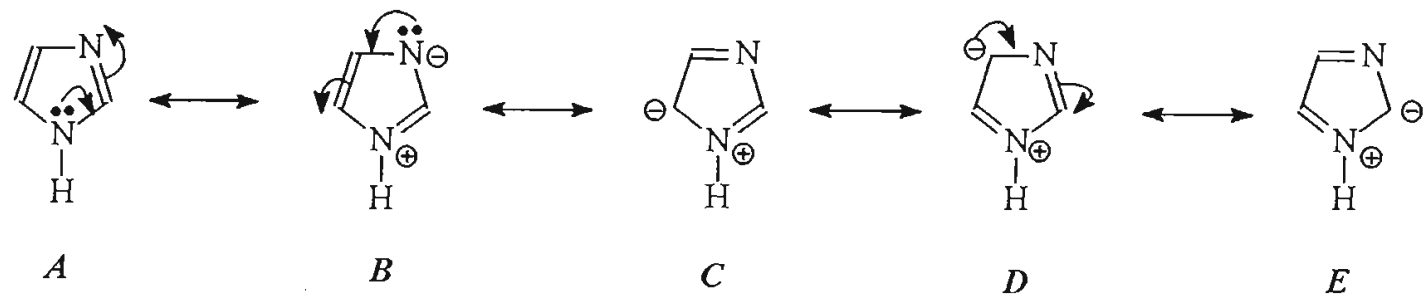

Figura 9: Formas canônicas do imidazol.

Porém, nem todas as formas canônicas dos imidazóis contribuem para a estrutura híbrida real na mesma medida. Assim, as formas $C$ e $D$, têm as cargas negativas estabilizadas, devido ao fato das mesmas estarem posicionadas entre os grupos $\mathrm{C}=\mathrm{N}$ e $\mathrm{C}=\mathrm{N}^{+}$, e sendo assim são mais importantes que a forma $E$, que não possui tal estabilização.

A presença de átomos de nitrogênio no anel tem importante efeito nas propriedades deste. No pirrol o elétron proveniente do nitrogênio impede o ataque aos átomos de carbono do anel, mas a presença do nitrogênio piridínico aumenta a tendência ao ataque eletrófilo nos átomos de carbono e diminui a tendência ao ataque dos átomos de nitrogênio. A substituição eletrófila ocorre mais facilmente nas posições $D$ e $E$, fato que pode ser justificado pela maior 
contribuição das formas canônicas $C$ e $D$ na estrutura híbrida real, dos imidazóis. O nitrogênio pirrólico trás um par de elétrons livre para o anel, o que favorece o ataque por prótons ou outros eletrófilos. Os efeitos do nitrogênio adicional, em relação a piridina, também podem ser vistos na acidez e basicidade desse heterocíclicos. O par de elétrons livre gera regiões para protonação, o que os torna bases mais fortes que o pirrol, e a presença do grupo $\mathrm{NH}$ os faz ácidos mais fortes, também, que o pirrol.

Em soluções ácidas, o hidrogênio do carbono 5 é duas vezes mais facilmente substituído do que o do carbono 4 e cem vezes mais facilmente do que o hidrogênio do carbono 2. Já em meio neutro ou fracamente alcalino a troca ocorre preferencialmente no carbono 2 .

Imidazóis com o grupo $\mathrm{NH}$ no anel estão sujeitos a tautomeria. Isso fica evidente em imidazóis substituídos como o metilimidazol. Esta especial característica da química dos imidazóis significa que não se pode escrever simplesmente 4-metilimidazol, pois esta molécula está em equilíbrio tautomérico com o 5-metilimidazol. Deve-se escrever então, 4(5)-metilimidazol. Em alguns pares uma das formas tautoméricas predomina. No caso do 4(5)-nitroimidazol predomina o isômero 4 na proporção de 400:1. No entanto, quando o hidrogênio do grupo NH está substituído a tautomeria desaparece. Agora a substituição dos átomos de carbono 2, 4 ou 5, gera a necessidade de ataques seletivos. 


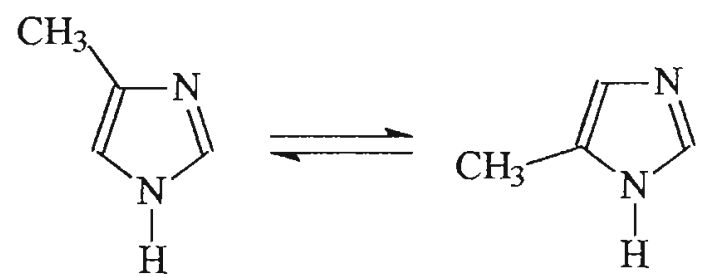

Figura 10: Equilibrio tautomérico do 4(5)-metilimidazol.

O método de síntese do anel imidazólico é a reação a partir de glioxal, formaldeído e amônia. Muitos dos métodos clássicos de síntese de imidazóis substituídos são baseados nesse tipo de reação (JOULE, SMITH, 1978, JOULE, MILLS, SMITH, 1995; DAVIES, 1992; GILCHRIST, 1985; POZHARSKII, SOLDATENKOV, KATRITZKY, 1996; YOUNG, 1978).

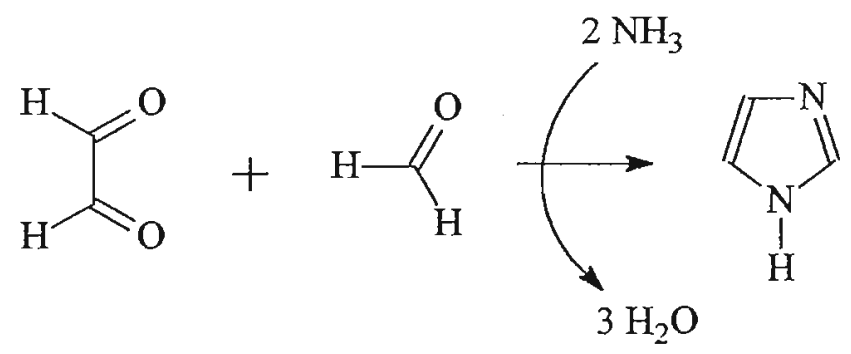

Figura 11: Formação do anel imid azólico.

As principais reações que ocorrem com o anel imidazólico são: (ver figura 12)

A: substituição eletrofilica preferencial na posição 5;

B: adição eletrofílica ao nitrogênio com formação de sais de imidazol;

C: regioseletividade da litiação na posição (bases fortes);

D: substituição no nitrogênio via sal de imidazol. 


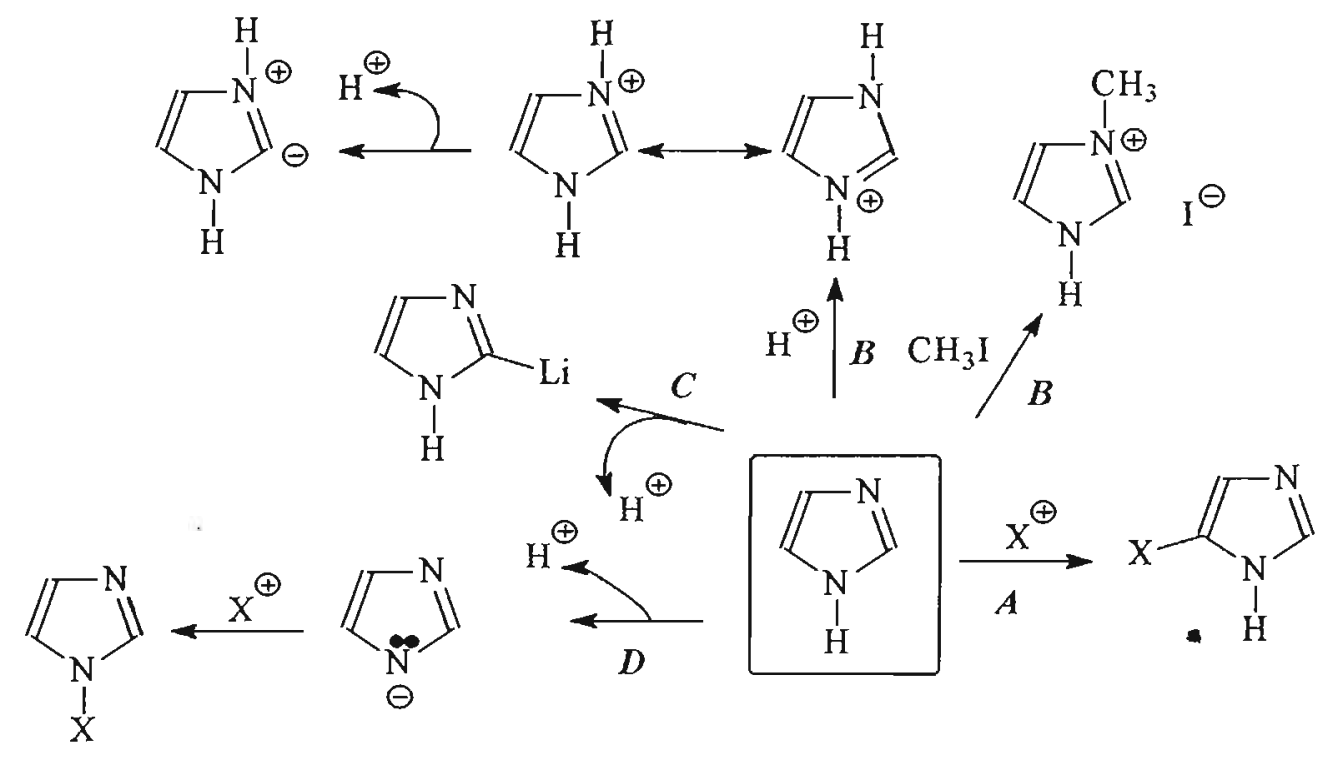

Figura 12: Esquema das principais reações do anel imidazólico.

\subsection{A DOENÇA DE CHAGAS}

Carlos Chagas, médico e pesquisador, teve sua atenção despertada pelo inseto hematófago Triatoma infestans, conhecido como barbeiro, que estava presente em enormes quantidades em casebres primitivos. Ao examinar o organismo do barbeiro ao microscópio, encontrou microorganismos ativíssimos pertencentes à família dos tripanossomas. Aquele inseto devia ser o transmissor da doença por ele pesquisada por ser portador de protozoários flagelados. Em pouco tempo ficou provado que os tripanossomas encontrados eram patogênicos. O protozoário ficou conhecido por Trypanosoma cruzi e em 1909 a nova doença encontrada recebeu o nome de doença de Chagas em homenagem a Carlos Chagas, descobridor não só do 
agente causador como também da forma de transmissão da doença, além de seus aspectos clínicos.

A doença de Chagas esteve restrita, inicialmente, aos animais da América, desde a Patagônia até o sul dos Estados Unidos da América. Com a chegada do homem e os processos de colonização, os barbeiros desalojados acabaram por invadir as habitações rústicas dos colonos. A doença chegou assim ao homem e aos mamíferos domésticos. Existem atualmente 18 milhões de pessoas infectadas, sendo que 6 ou 7 milhões estão no Brasil, o que torna a doença de Chagas um problema médico e social de grande porte na América Latina (DIAS, JATENE, 1992; DO CAMPO, MARR, 1986).

A contaminação se dá através das fezes do inseto. $\mathrm{O}$ parasita entra na corrente sanguínea pela pequena lesão deixada pela picada do barbeiro, que provoca coceira. Ao se coçar a vítima involuntariamente se contamina. Os sinais da doença se produzem no próprio lugar onde se deu a infeç̧ão. Se a contaminação se dá na região próxima aos olhos, esses fícam inchados. Na pele a lesão inicial assemelha-se a um funúnculo ou mancha avermelhada quase sempre dolorosa. Ocorre a formação de ínguas.

Na fase aguda da doença ocorre febre, a quantidade de parasitas circulantes é grande e após algumas semanas os sintomas desaparecem. Porém, em crianças pode haver morte, em face de um ataque intensivo dos tripanossomas. Em adultos a fase aguda, é mais atenuada, podendo passar despercebida ou confundida com uma gripe. 
A fase crônica é afebril, com poucos parasitas em circulação e muitos indivíduos podem passar um longo período de tempo, ou até mesmo a vida toda, sem apresentar sintomas da doença.

No estágio crônico da doença o coração é o órgão mais lesado, devido à preferência dos tripanossomas por suas fibras musculares. $O$ órgão entra em grave desorganização na maneira de contrair-se, as batidas ficam irregulares, podendo ocorrer morte súbita.

O aparelho digestivo também sofre a ação do parasitas. Há um aumento do calibre do esôfago e das porções finais do intestino, provocando dificuldades para deglutir e prisão de ventre. $\mathrm{O}$ indivíduo pode ficar meses sem evacuar.

Apesar de muitas pesquisas e de grandes progressos alcançados no estudo da doença; o tratamento apresenta, ainda hoje, muitos problemas. $\mathrm{O}$ modo de tratamento é dividido em uma terapêutica específica, ou seja, contra o parasita e uma terapêutica sintomática, onde há atenuação dos sintomas das lesões já provocadas pela doença (BRENER, 1979; DE CASTRO, 1993)

O protozoário se abriga na intimidade de várias células, o que torna mais dificil atacá-lo. Muitos fármacos que se mostraram ativos para outras infeç̧ões são inócuos ao Trypanosoma cruzi. 
Este parasita se caracteriza por interagir com o sistema imunológico do doente, o que dificulta sua erradicação bem como o desenvolvimento de vacinas específicas.

Nos anos 60, fármacos eficazes começaram a serem utilizados, como os nitrofuranos. O mais efetivo foi o nifurtimox (13) que levou a casos de cura em ambas as fases. Mais adiante, um derivado imidazólico denominado benzonidazol (14) mostrou-se mais potente contra o parasita (ANDRADE, MAGALHÃES, PONTES, 1985).

\subsubsection{Terapêutica Experimental na doença de Chagas}

O controle de transmissão da doença de Chagas por inseticidas de longa duração, o aperfeiçoamento do processo de transfusão de sangue e a drástica redução da população rural têm diminuído os índices de contaminação em largas áreas do Continente Americano. Apesar dessa conquista, permanecem milhões de pacientes chagásicos que necessitam de atendimento médico e tratamento específico.

Séries de fármacos foram testadas, a partir da década de 50 , em animais e pacientes chagásicos sem êxito, e somente a partir de 1970 é que os dois fármacos citados anteriomente atingiram o mercado, embora com limitações. 


\subsubsection{Nifurtimox (13) e Benzonidazol (14)}

Em 1972, o nifurtimox (13) foi usado em animais inoculados com oito cepas do Trypanosoma cruzi, obtendo bons resultados, e, após estudos farmacológicos, o fármaco foi submetido em humanos nas fases aguda e crônica da doença. Na Argentina verificou-se uma porcentagem de cura de $81 \%$ dos pacientes. Já no Brasil Central a cura foi de cerca de $47 \%$.

Em 1978, o benzonidazol (14) foi empregado no tratamento específico de pacientes chagásicos na fase aguda, promovendo curas parasitológicas de $50 \%$ a $70 \%$. No tratamento de pacientes crônicos os resultados são significativamente inferiores.<smiles>CC1CS(=O)(=O)CCN1N=Cc1ccc([N+](=O)[O-])o1</smiles>

nifurtimox (13)<smiles>O=C([O-])Cn1ccnc1C(=O)Nc1ccccc1</smiles>

benzonidazol (14)

Figura 13: Fármacos com atividade antichagásica.

Esses fármacos são moderadamente tóxicos e podem eliminar o parasita do sangue e dos tecidos se administrados na dose e no tempo corretos. Ainda assim, o tratamento exige cuidado devido às reações colaterais de gravidade variáveis (BRENER, 1979; CRUZ, VILLALTA, MUNIZ, 1981). Sendo assim, há muitas restrições quanto ao seu uso, o que acabou tirando o nifurtimox (13) do mercado. 
Atualmente, o benzonidazol (14) é o único medicamento empregado, mas seu uso é restrito à área hospitalar, não sendo mais comercializado. Estes fatos indicam claramente a necessidade de mais compostos ativos contra o Trypanosoma cruzi a serem estudados e desenvolvidos, visando uma alternativa terapêutica.

A seleção de fármacos para o tratamento da doença de Chagas faz-se através de modelos que avaliam a eficiência das moléculas em relação aos estágios evolutivos do Trypanosoma cruzi, obtidos de camundongos infectados.

Estudos realizados em 1967 mostraram que a suscetibilidade da cepa Tulahuen foi significativamente menor em um grupo de sete cepas submetidas ao tratamento específico. Mais recentemente foi demonstrado que havia uma correlação entre a resistência ao nifurtimox (13) e benzonidazol (14) com características morfobiológicas das cepas do Trypanosoma cruzi. Além disso, detectou-se a existência de cepas de alta resistência isoladas na cidade de Montalvânia em Minas Gerais. Esses dados levantaram a possibilidade de que certas cepas resistentes predominem em determinadas áreas geográficas, fato que explicaria resultados contraditórios nos tratamentos clínicos com os derivados nitroeterocíclicos.

Um trabalho realizado em 1987 mostrou a suscetibilidade do nifurtimox (13) e benzonidazol (14) em 47 cepas de Trypanosoma 
cruzi isoladas de diferentes hospedeiros, áreas geográficas e origem das fases agudas e crônicas. As cepas foram depositadas em um criobanco mantido pelo Laboratório de Doença de Chagas da Fundação Oswaldo Cruz, em Belo Horizonte. Nesse estudo, as cepas foram inoculadas em camundongos fêmeas Swiss albino, sendo estes tratados com os fármacos benzonidazol (14) e nifurtimox (13), por 20 dias consecutivos, nas dosagens de $100 \mathrm{mg} / \mathrm{kg}$. Os grupos de 15 animais, mantidos por 30 a 45 dias, foram submetidos aos testes de hemocultura e de imunofluorescência. Os resultados desse levantamento mostraram nítida distribuição geográfica de diferentes cepas do Trypanosoma cruzi. Assim, cepas isoladas do Rio Grande do Sul e Argentina apresentam alta suscetibilidade, ao passo que as provenientes de Minas Gerais são resistentes. Esses dados são compatíveis com o relato da existência de um número de cepas altamente resistentes em Montalvânia, área na qual ocorreu recente invasão pelo Triatoma infestans. (BRENER, ANDRADE, BARRAL-NETTO, 2000).

\subsection{MEGAZOL (12)}

No final dos anos 60, o megazol (12), sintetizado por Berkalhammer e Asato, demonstrou possuir largo espectro de ação biológica, revelando também sua eficácia contra o parasita causador da doença de Chagas. A literatura descreve quatro rotas para sua obtenção (BERKELHAMMER, ASATO, 1968; REMERS, GIBS, WEISS, 1969; REMERS et al, 1972, ALBRIGHT, SHEPHERD, 1973; ALBUQUERQUE, 1995). 
Apesar de ter demonstrado largo espectro de atividade biológica frente a diversos microorganismos gram-positivos e gramnegativos (BURDEN, RACETTE, 1968; NAIR, NAGARAJAN, 1983; WINKELMANN et al, 1977), bem como fungos e parasitas, o estudo não foi continuado devido ao potencial tóxico do grupo nitro, presente na molécula, que apresentava restrições mediante o registro de novos fármacos pelo $\mathrm{FDA}$.

A gravidade da infecção pelo parasita no Brasil levou os pesquisadores, nos anos 80, a relacionarem um grande número de moléculas com potencial antichagásico. Entre elas, o megazol (12) figura como um fármaco de grande interesse (FILARD, BRENER, 1982; TSUHAKO et al, 1989; TSUHAKO, 1990).

A atividade quimioterápica com megazol (12) foi determinada a partir de uma variedade de experimentos em animais de laboratório infectados por protozoários. Estes incluem Tricomonas vaginalis em camundongos, Entamoeba histolytica em camundongos e hamsters, Trypanosoma cruzi e Leishmania donovani em camundongos. Os níveis de atividade e o relativo potencial referente aos dados obtidos variaram de acordo com os diferentes testes empregados.

Infecções com Tricomonas vaginalis em camundongos responderam com dose oral única ou múltipla de megazol (12) na concentração de $10 \mathrm{mg}$ por $\mathrm{kg}$. Doses de 90 a $130 \mathrm{mg}$ por $\mathrm{kg}$ por dia resultaram em 100\% de cura. Dependendo do método de tratamento, os 
níveis de potencialidade do megazol (12), em tricomoníases experimentais, foram de 2 a 8 vezes mais eficientes que o metronidazol (5) com margem de segurança equivalente ou superior.

Em 1968, a partir de testes realizados pela American Cianamid, constatou-se que dose única via oral ou intraperitoneal entre 20 a $40 \mathrm{mg}$ por $\mathrm{kg}$ prolongou a sobrevivência de ratos e camundongos infectados experimentalmente em cepas altamente virulentas do Trypanosoma equiperdum. A ingestão de 6 a $13 \mathrm{mg}$ por $\mathrm{kg}$ por dia durante sete dias foi também altamente supressiva, em infecções experimentais de roedores, causadas por um tipo virulento de Trypanosoma cruzi.

Em testes laboratoriais também foi evidenciada a eficácia do megazol (12), em ratos que receberam doses únicas via oral ou subcutânea, frente a bactérias gram-positivas e gram-negativas. Este fármaco foi tão potente quanto o ácido nalidíxico (15), fármaco de referência contra infecções produzidas por bactérias patogênicas gramnegativas.<smiles></smiles>

Figura 14: Estrutura do ácido nalidíxico. 
Experiências com o Trypanosoma cruzi foram efetuadas na fundação Oswaldo Cruz, Rio de Janeiro. Após administrar o medicamento em camundongos concluíram que esse fármaco é o mais ativo componente já testado e pode ser adicionado à lista existente de fármacos com marcante atividade contra o Trypanosoma cruzi.

Os níveis de potencialidade mencionados nestes experimentos mostram dados suficientemente interessantes para justificar outros estudos.

\subsection{ROTAS DE OBTENÇÃO DO MEGAZOL (12)}

A primeira rota de síntese relatada, foi proposta por Berkelhammer e Asato, em 1968, como demonstrado abaixo.

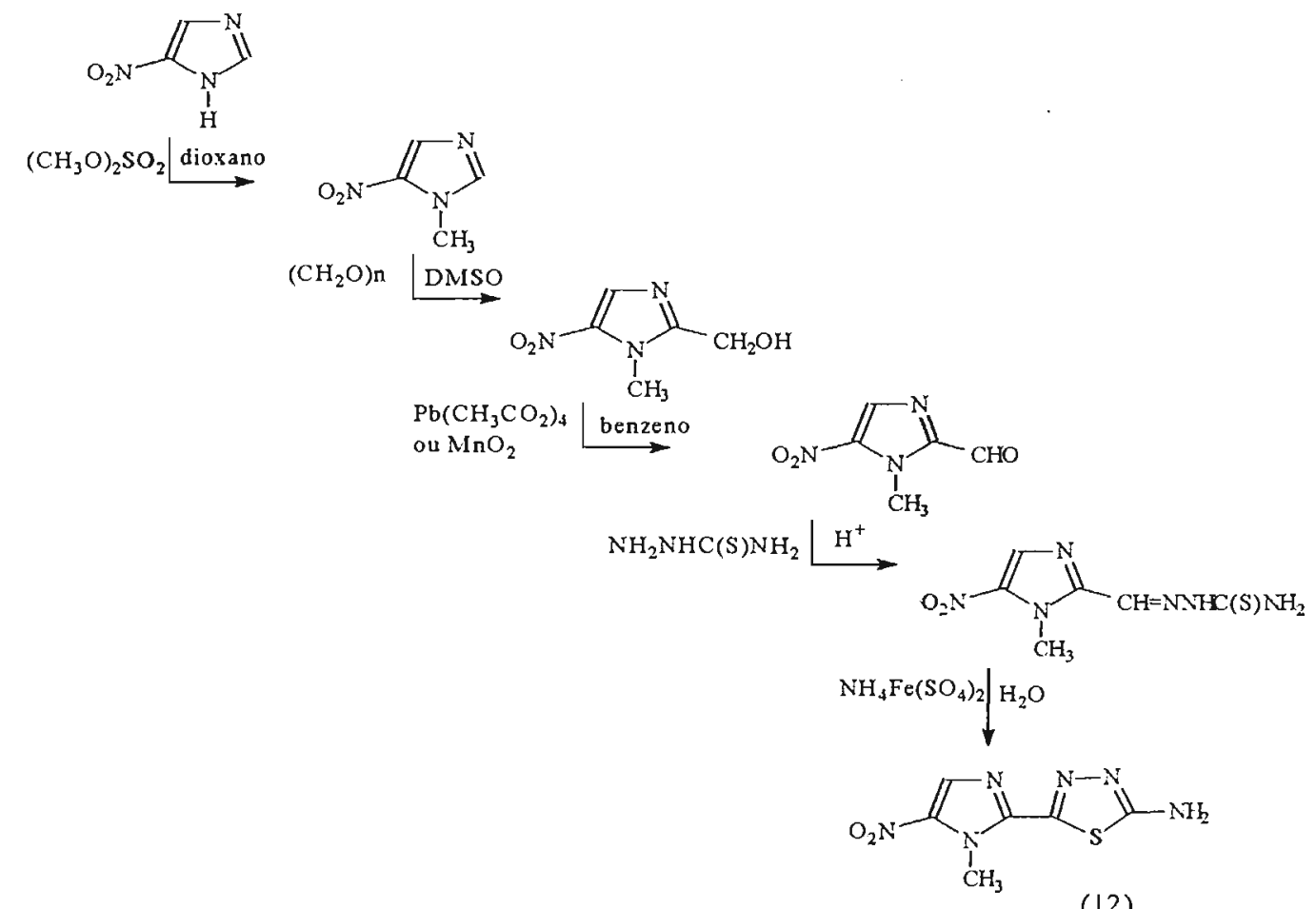

Figura 15: Esquema de síntese do megazol (12), descrito por Berkelhammer e Asato, em 1968. 
O método utiliza o 4(5)-nitroimidazol como produto de partida, que foi metilado na posição 1 utilizando-se dimetilsulfato em meio aprótico neutro.

O produto desta reação foi hidroximetilado na posição 2 , utilizando-se paraformaldeído em dimetilsulfóxido e o álcool produzido foi oxidado ao aldeído correspondente pela ação de tetracetato de chumbo ou por dióxido de manganês.

Este aldeído foi submetido à reação com tiosemicarbazida em meio ácido ou neutro produzindo a tiosemicarbazona correspondente. Esta última, sob ação oxidante do sal duplo de ferro e amônio produziu o megazol (12), com um rendimento global de 4\%.

A segunda rota foi proposta em 1969 por Remers, Gibs e Weiss. Baseava-se na formação inicial do anel tiadiazólico a partir da tiosemicarbazida, finalizando com a formação do anel imidazólico para a obtenção do megazol (12), como se pode observar na figura a seguir. 


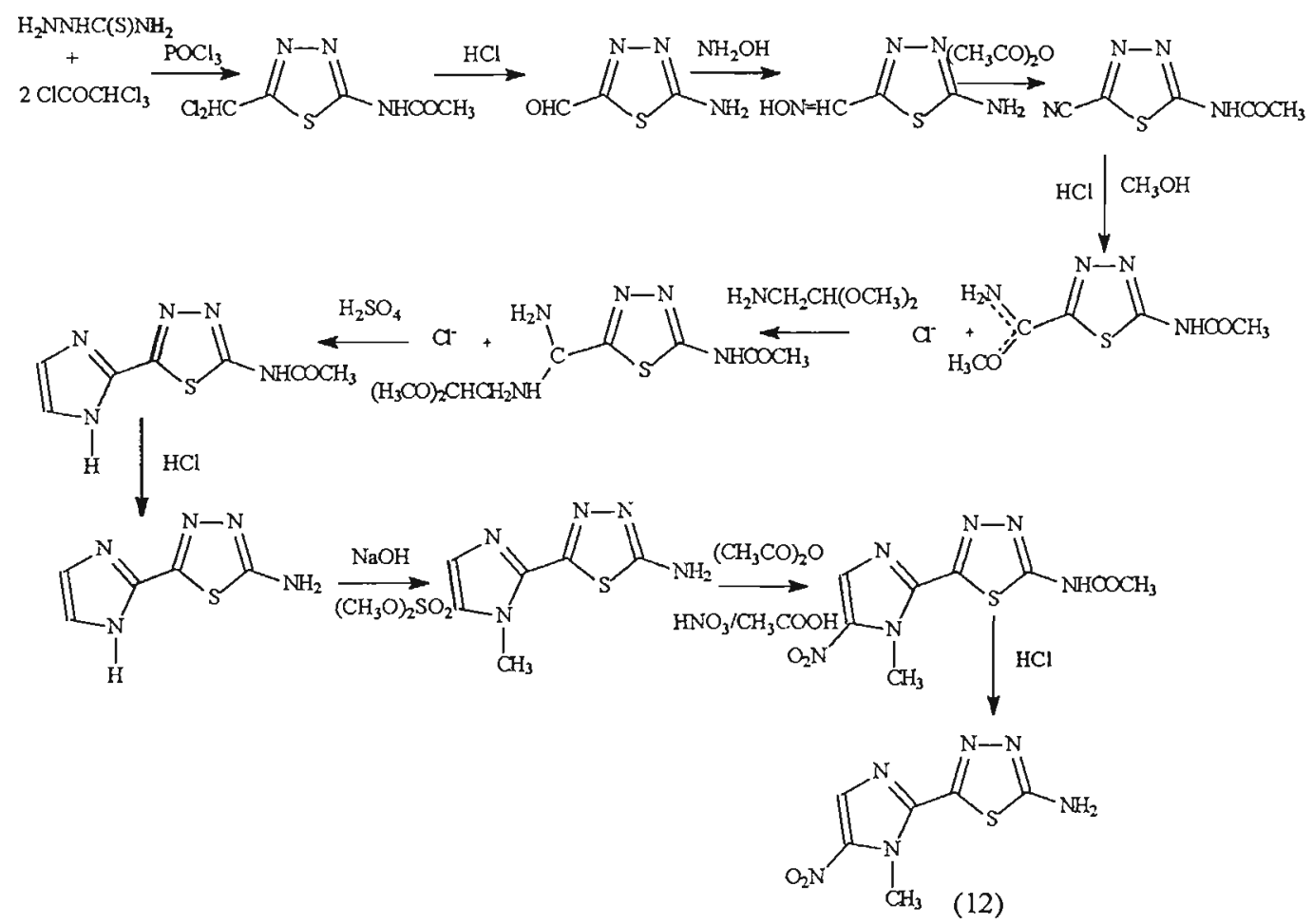

Figura 16: Esquema de síntese do megazol (12), proposto por Remers, Gibs e Weiss, em 1969.

Esta rota partiu da tiosemicarbazida que, reagindo tanto com cloretos de ácidos halogenados como anidridos dos mesmos, formou o anel tiadiazólico funcionalizado na posição 5 .

O processo de ciclização foi realizado pela ação do ácido sulfúrico, obtendo-se o anel imidazólico. Este foi então metilado pelo dimetilsulfato e, após proteção da amina do anel tiadiazólico, efetuouse o processo de nitração. O megazol (12) foi então obtido por hidrólise ácida da amida com um rendimento global final em torno de $1 \%$. 
Uma terceira rota foi formulada por Albright e Shephard em 1973, que se baseava na reatividade do grupamento metila em posição 2 do anel nitroimidazólico. Esta rota sintética apresentou um rendimento global de $12 \%$, tendo sido executada em 4 etapas:

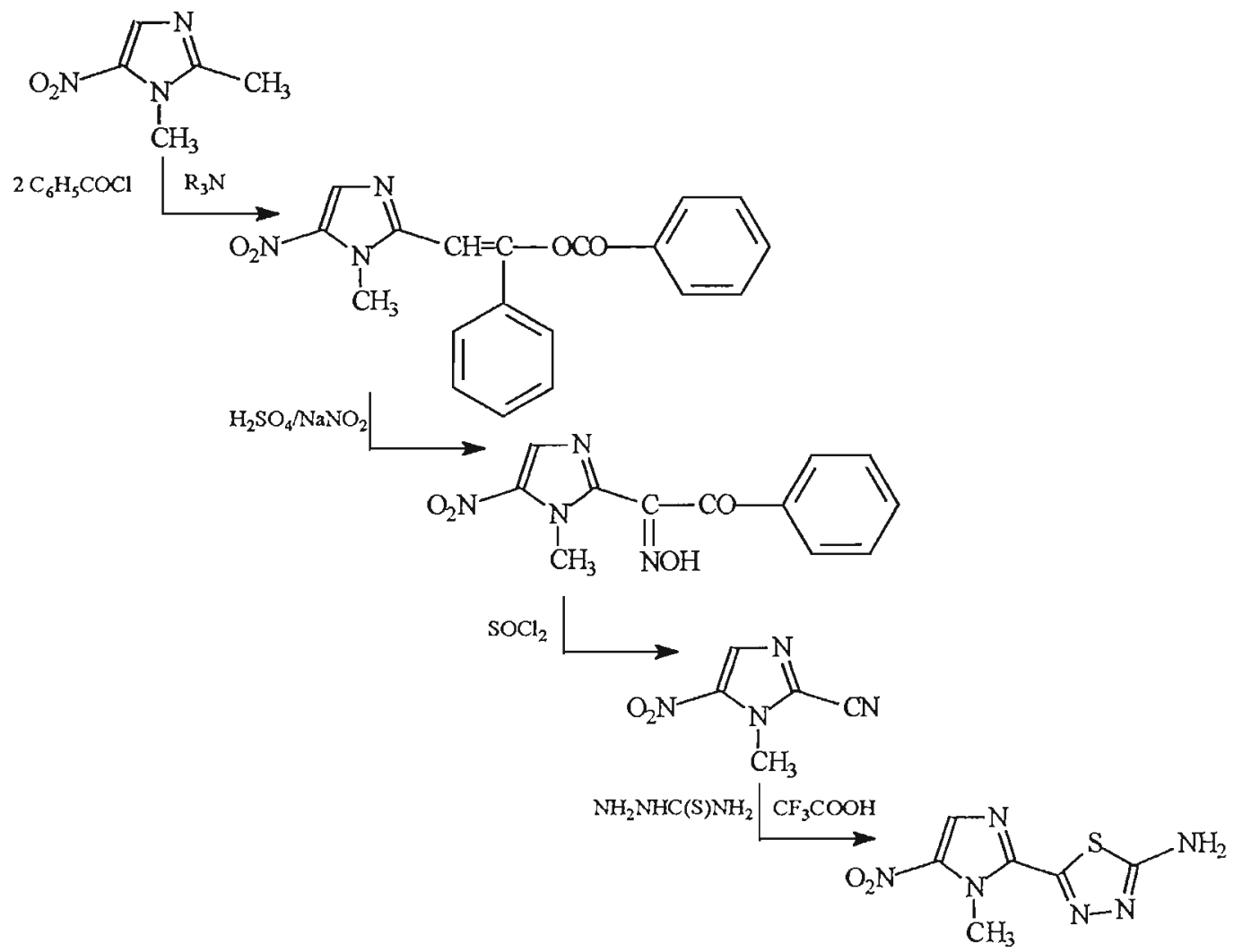

(12)

Figura 17: Esquema de síntese do megazol (12), proposto por Albrigth e Shephard, em 1973.

O material de partida utilizado foi o 1,2-dimetil-5-nitroimidazol que reagiu com cloreto de benzoíla em presença de uma amina terciária.

O produto desta reação reagiu com nitrito de sódio em presença de ácido sulfúrico formando a oxima correspondente que, sob ação do cloreto de tionila, produziu a nitrila na posição 2. Este foi o intermediário chave do processo e reagiu facilmente com a 
tiosemicarbazida em meio de ácido trifluoracético dando o megazol (12).

Com base na química de nitroimidazóis e em experimentações anteriores das rotas citadas, foi formulado, um novo caminho para a obtenção do megazol (12):

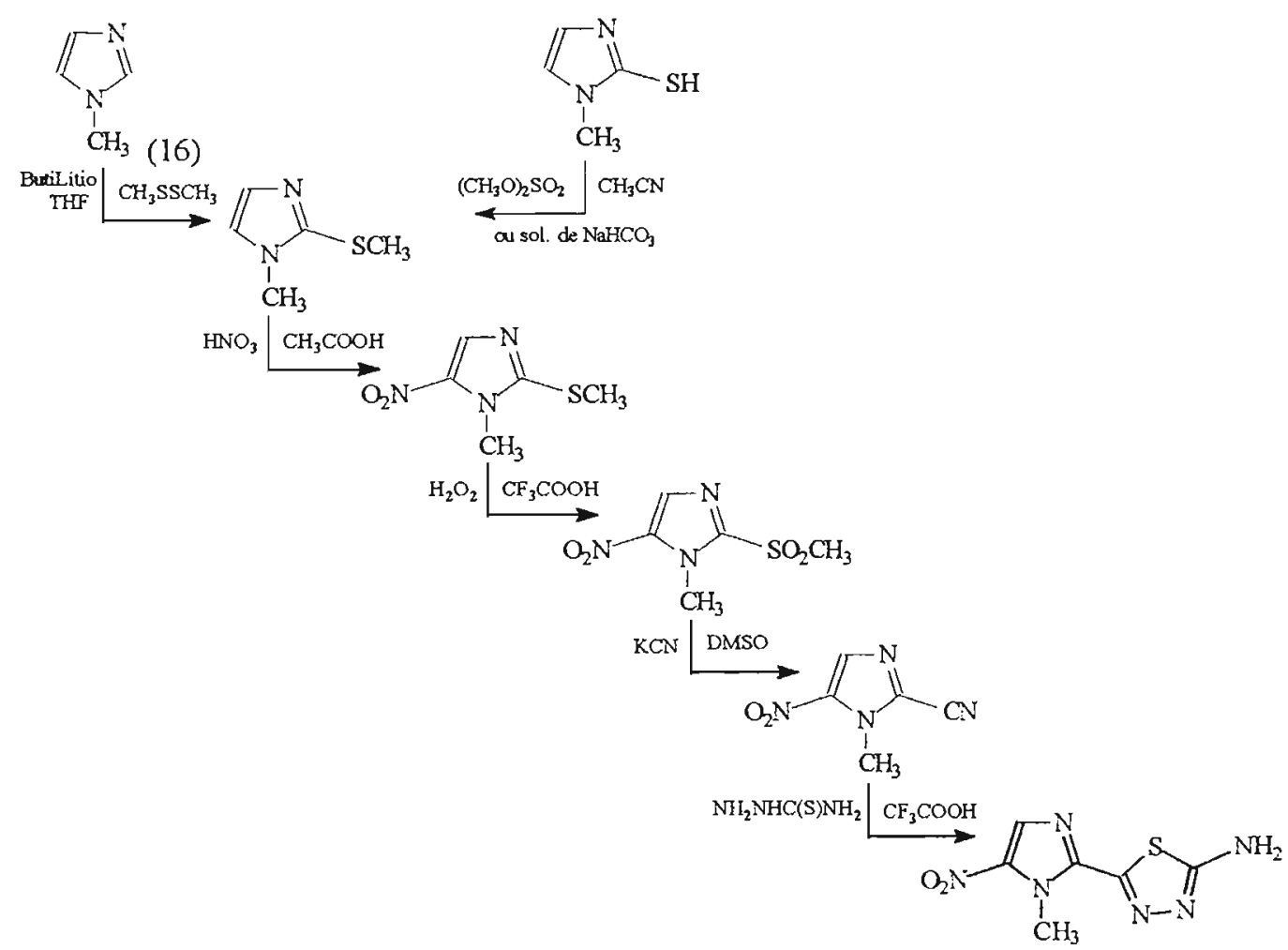

(12)

Figura 18: Rota de síntese proposta para obtenção do megazol (12), por Albuquerque e col, em 1995.

Esta rota pode empregar duas matérias-primas: o 1metilimidazol (16) que foi funcionalizado na posição 2 pela ação do butil-lítio e do dimetildissulfeto, ou o 1-metil-2-tioimidazol que foi metilado pela ação do dimetilssulfato em acetonitrila ou solução de bicarbonato de sódio. 
O composto 1-metil-2-tiometilimidazol foi nitrado em posição 5 pelo ácido nítrico a $69 \%$ em ácido acético. O 5-nitroimidazol foi submetido à oxidação para produzir a sulfona correspondente, a qual por reação com cianeto de potássio, levou ao 1-metil-2-ciano-5nitroimidazol, intermediário chave desta rota.

$\mathrm{Na}$ última etapa efetuou-se a reação da nitrila com tiosemicarbazida, em presença de ácido trifluoracético para conduzir ao produto desejado, o megazol (12). Os rendimentos globais utilizando-se o 1-metilimidazol (16) e o 1-metil-2-tioimidazol como materiais de partida foram de 7 e $5,5 \%$.

Em 2001, Moretto retomando esta rota, estudou alguns processos visando aumentar o rendimento das etapas limitantes como a nitração, que rendia $22 \%$ do produto desejado. A partir de dados experimentais a rota foi modificada segundo indicado na figura a seguir:

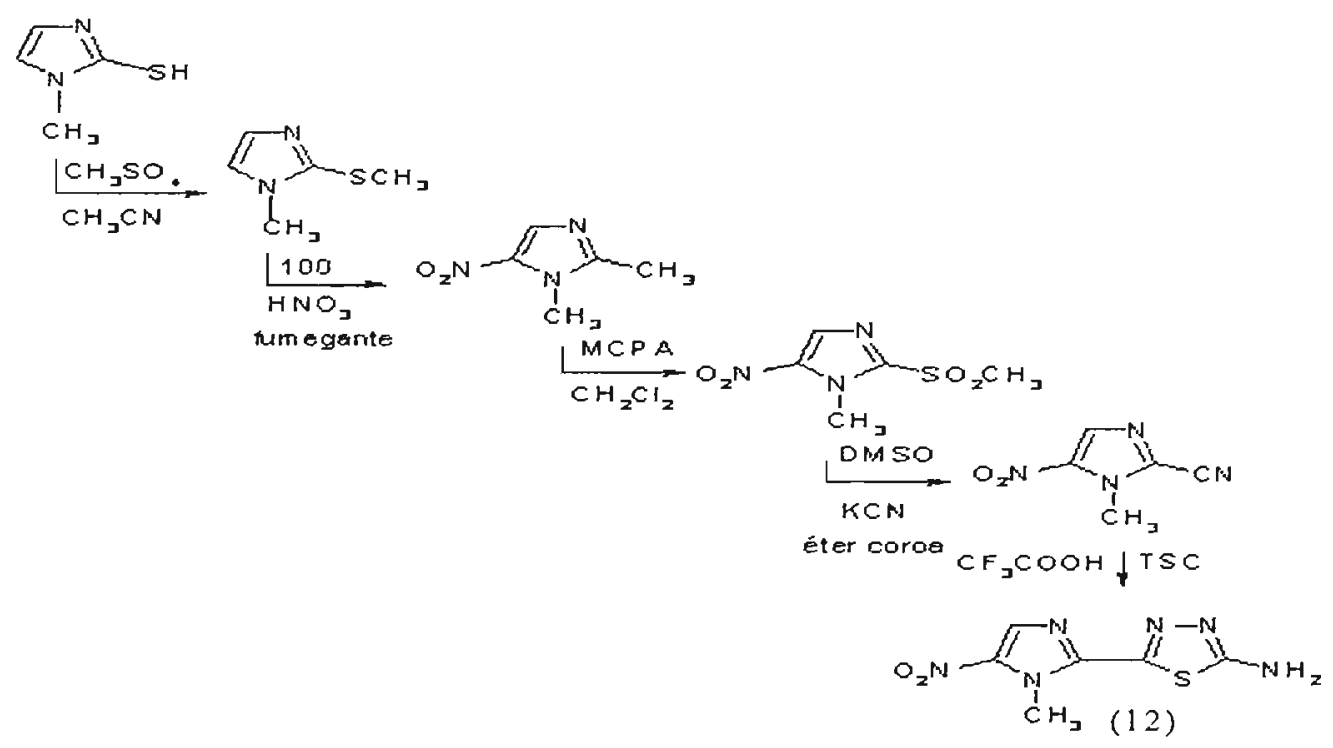

Figura 19: Rota de síntese do megazol (12), otimizada por Moretto, em 2001. 
Nesta alternativa foi utilizada como matéria-prima $o$ composto 1-metil-2-tioimidazol que foi metilado pelo dimetilsulfato em acetonitrila. O produto obtido foi nitrado com ácido nítrico fumegante a aproximadamente $100^{\circ} \mathrm{C}$ atingindo um rendimento de $40 \%$ do produto nitrado desejado. A sulfona foi então obtida, por oxidação, empregando o ácido metacloroperbenzóico em diclorometano, atingindo um rendimento de $95 \%$ do produto oxidado. Seguiu-se a substituição da sulfona pelo grupo ciano e ciclização do produto obtido com a tiosemicarbazida, sem alterações nas metodologias originais e com manutenção dos rendimentos. Essa otimização ampliou o rendimento global da rota estudada de $7 \%$ para $12 \%$.

Após diversos fracassos experimentais foi encontrada uma metodologia simples, apesar de empregar um agente lacrimogênio $(\mathrm{BrCN})$, mas bastante viável na cianação de imidazóis na posição 2 (WHITTEN, MACCARTHY, MATTHEWS, 1985, 1986, 1988).

A partir deste fato foi formulada uma rota alternativa para a obtenção do megazol (12).

Partiu-se do 1-metilimidazol (16), empregando a metodologia de cianação pela formação do complexo dimetilaminopiridina com brometo de cianogênio em dimetilformamida anidra. Segundo a literatura, a obtenção do 1-metil2-cianoimidazol (17) ocorre com um rendimento de 78\% (WHITTEN, MACCARTHY, MATTHEWS, 1985, 1986, 1988). 
As etapas de ciclização, utilizando ácido trifluoracético, e de nitração apresentam rendimentos de $60 \%$ e $20 \%$, respectivamente (ALBUQUERQUE, 1995; REMERS et al, 1969, 1972). Logo, é esperado um aumento tanto no tempo de execução, pelo menor número de etapas, como também no rendimento global (em torno de 15\%). 


\section{OBJETIVO}

Este trabalho tem como objetivo o estudo de uma nova rota de síntese do megazol (12) que promova uma alternativa na produção dessa molécula, não só utilizando processos de fácil execução, como também diminuição no tempo de execução do fármaco pelo menor número de etapas. A previsão do aumento dos rendimentos parciais deverá elevar o rendimento global para $15 \%$.

A partir de dados da literatura propõe-se a obtenção do megazol (12) a partir do 1-metilimidazol (16) (WHITTEN, MACCARTHY, MATTHEWS, 1985, 1986, 1988).

Esta rota é composta por três etapas de fácil execução, sendo a primeira a cianação do anel imidazólico na posição 2 e posterior ciclização deste intermediário através da reação da tiosemicarbazida em meio ácido formando o anel tiadiazólico (ALBUQUERQUE, 1995). A etapa final é a nitração do anel imidazólico e obtenção do megazol (12) (REMERS et al, 1969, 1972).

Visando a seqüência do estudo do megazol (12) e considerando as características do anel imidazólico, a rota em questão está representada na figura a seguir: 

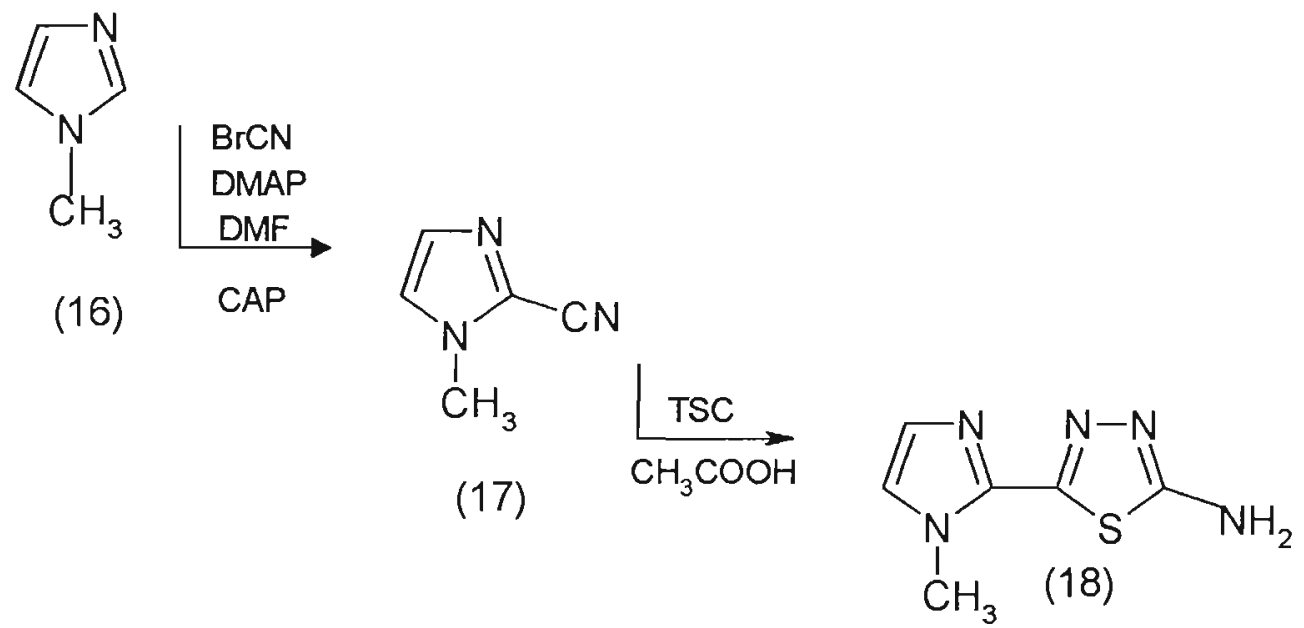<smiles>Cn1c([N+](=O)[O-])cnc1-c1nnc(N)s1</smiles>

(12)

Figura 20: Esquema da nova rota proposta para síntese do megazol (12). 


\section{MATERIAIS E MÉTODOS}

\subsection{MATERIAIS}

\subsubsection{Solventes}

Acetato de etila PA; diclorometano PA; éter etílico PA; acetona PA; metanol PA; dimetilformamida; tetraidrofurano.

A dimetilformamida foi destilada para a eliminação de água, pois esta interfere no processo de cianação.

\subsubsection{Reagentes}

1,4-dimetilaminopiridina; 1-metilimidazol (16); brometo de cianogênio; tiosemicarbazida; ácido nítrico fumegante; ácido nítrico $70 \%$; ácido acético; hidróxido de amônio 32\%; ácido trifluoracético; bicarbonato de sódio; ácido clorídrico; anidrido acético; cloreto de amônio, sílica gel 60 para coluna cromatográfica, tamanho de partículas $63-200$ mesh e $70-230$ mesh, Merck.

\subsubsection{Equipamentos}

As evaporações foram realizadas em evaporador rotatório marca Marconi.

Os produtos sintetizados foram identificados por comparação com padrões previamente preparados por cromatografia em camada delgada efetuadas com folhas de alumínio recobertas de sílica gel 60 mesh com indicador de fluorescência marca Merck 60F257. Estas 
placas cromatográficas foram reveladas pela exposição à lâmpada UV $(254 \mathrm{~nm})$.

Os dados de ressonância magnética nuclear unidimensional de hidrogênio ( $\left.{ }^{1} \mathrm{H} \mathrm{RMN}\right)$, e de carbono $\left({ }^{13} \mathrm{C} \mathrm{RMN}\right)$ foram obtidos em aparelho Bruker ADVANCE DPX-300 (300MHz). O solvente utilizado para os experimentos foi o DMSO deuterado. Os deslocamentos químicos $(\delta)$ foram expressos em ppm em relação ao tetrametilsilano (TMS), utilizado como padrão interno.

Para determinação dos pontos de fusão das moléculas sintetizadas foi utilizado o aparelho da marca Marconi para este fim, sem correção.

\subsection{MÉTODOS}

\subsubsection{Primeira etapa - Cianação}

Em um balão de fundo redondo adicionar $6,1 \mathrm{~g}$ de dimetilaminopiridina em $100 \mathrm{~mL}$ de dimetilformamida (recémdestilada). Colocar em banho de gelo com sal grosso e adicionar $5,3 \mathrm{~g}$ de brometo de cianogênio. Conectar em balão com condensador de refluxo. Deixar em baixa temperatura durante 15 minutos sob agitação. Forma-se uma emulsão amarela, indicando a formação do C.A.P. Adicionar, então, 1,7 mL de 1-metilimidazol (16). Retirar o banho de gelo. Aquecer a $40^{\circ} \mathrm{C}$ por 20 horas, ainda sob agitação. Ao final, obtém-se uma solução marrom com a formação de um precipitado. Filtrar, desprezando o precipitado, verificar o $\mathrm{pH}$ neutralizando com 
solução saturada de bicarbonato de sódio. Extrair o produto com diclorometano.

Para a eliminação da dimetilformamida, extrair com solução aquosa 1 equivalente-grama por litro de cloreto de amônio. A fração aquosa é descartada e a fração com diclorometano evaporada.

A purificação do produto concentrado é feita em coluna com sílica gel e diclorometano. Adicionar a amostra a purificar e o eluente adequado $(2,5 \%$ em volume de metanol em diclorometano). Cromatografar as alíquotas que saírem da coluna e verificar onde o produto está mais puro. Evaporar as frações. O produto é um óleo marrom.

Análise:

RMN'H (DMSO) $\delta \mathrm{ppm}=3,49\left(\mathrm{~s}, 3 \mathrm{H}, \mathrm{NCH}_{3}\right) ; 8.03(\mathrm{~s}, 1 \mathrm{H}, \mathrm{H} 5) ; 8,36$ (s, 1H, H4).

$\mathrm{RMN}^{13} \mathrm{C}(\mathrm{DMSO}) \delta \mathrm{ppm}=30,66\left(\mathrm{NCH}_{3}\right) ; 79,06(\mathrm{CN}) ; 130,90(\mathrm{C} 2)$; 162,23 (C4 e C5).

\subsubsection{Segunda etapa - ciclização}

Em um balão de fundo redondo dissolver o 1-metil-2cianoimidazol (17) em ácido trifluoracético. Adicionar a tiosemicarbazida, deixando sob agitação a $40^{\circ} \mathrm{C}$ por uma noite. A proporção entre os reagentes deverá ser 1:1 em mol e a quantidade do ácido suficiente para dissolver a tiosemicarbazida. Dois $\mathrm{mL}$ do ácido para cada 5 mmols do produto cianado foram suficientes. 
Transcorrida a reação o meio deve ser neutralizado com solução aquosa de hidróxido de amônio. Forma-se um precipitado bege que é filtrado e lavado com água gelada. Recristalizar em etanol se necessário. Precipita um sólido branco.

Análise:

RMN'H (DMSO) $\delta \mathrm{ppm}=4,06\left(\mathrm{~s}, 3 \mathrm{H}, \mathrm{NCH}_{3}\right) ; 4,49\left(\mathrm{~b}, 2 \mathrm{H}, \mathrm{NH}_{2}\right)$; 7,24 (s, 1H, C4); 7,49 (s, 1H, C5).

$\mathrm{RMN}^{13} \mathrm{C}$ (DMSO) $\delta \mathrm{ppm}=35,315\left(\mathrm{NCH}_{3}\right) ; 125,030(\mathrm{C} 5) ; 126,393$ (C4); 136,166 (C2); 150,142 (C2'); 170,454 (C5').

\subsubsection{Terceira etapa - nitração}

Uma mistura de $0,7 \mathrm{mmoL}$ do produto ciclizado e $0,4 \mathrm{~mL}$ de anidrido acético é aquecida em banho-maria por 5 minutos. À amida resultante misturou-se $1,2 \mathrm{~mL}$ de ácido acético, $0,05 \mathrm{~mL}$ de ácido nítrico $70 \%$ e $0,2 \mathrm{~mL}$ de anidrido acético. Ocorre uma reação violenta com liberação de vapores nitrosos que após 10 minutos clareia. A mistura é concentrada e o resíduo tratado com água. Lavar o sólido amarelo que se forma e secar ao ar, obtendo-se o megazol acetilado. Tratar a mistura, de mais ou menos $60 \mathrm{mg}$, com $0,2 \mathrm{~mL}$ de ácido clorídrico concentrado e aquecer em banho-maria por 15 minutos. Após o resfriamento concentrar a vácuo. Neutralizar o resíduo $(\mathrm{pH}=7)$ com solução de hidróxido de amônio, ou solução saturada de bicarbonato de sódio. Precipita um sólido. Este sólido é lavado com água e seco ao ar. 


\section{PROPOSIÇÃO DE NOVA ROTA DE SÍNTESE DO MEGAZOL}

(12)

Baseando-se em dados de literatura sobre síntese de imidazóis propõe-se uma nova rota de obtenção do megazol (12) cujas etapas serão descritas abaixo.

\subsection{CIANAÇÃO}

O novo método proposto tem como produto de partida o 1metilimidazol (16). Este é funcionalizado na posição dois, pela introdução de um grupamento ciano. Para esta reação emprega-se o brometo de cianogênio, porém a reação direta de imidazóis com brometo de cianogênio resulta em bromoimidazóis, não havendo, portanto, um método direto para obtenção de 2-cianoimidazóis. A literatura indica a síntese desta classe de compostos pela ação do C.A.P., que é um complexo formado entre o brometo de cianogênio e 1,4-dimetilaminopiridina em dimetilformamida, resultando no sal brometo de 1-ciano-4-dimetilaminopiridina (C.A.P.), de acordo com o esquema abaixo:<smiles>CN(C)c1cc[n+](C#N)cc1</smiles>

Figura 21: Formação do C.A.P.

Este complexo ataca a ligação carbono-hidrogênio do anel imidazólico na posição dois, promovendo a formação da ligação carbono-carbono entre o anel e o grupo ciano. Esta conversão se 
caracteriza pela formação da espécie eletrofílica $\mathrm{CN}^{+}$. Obtém-se, então, o 1-metil-2-cianoimidazol (17), conforme o esquema abaixo:

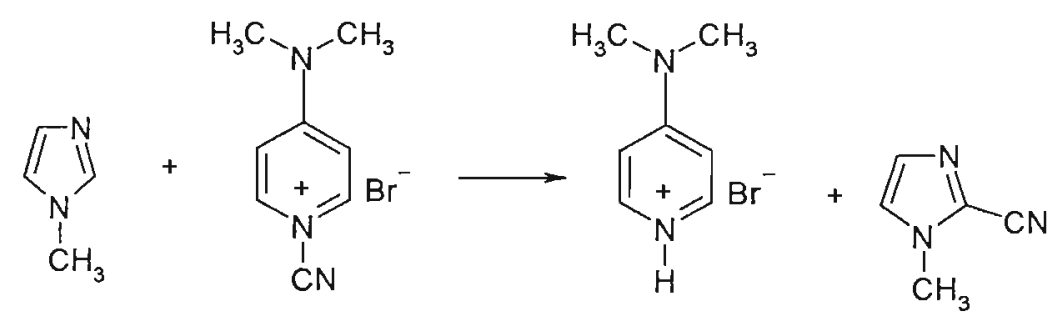

Figura 22: Mecanismo proposto para cianação do 1-metilimidazol (16), via C.A.P.

A síntese de 2-cianoimidazóis é também descrita utilizando cloreto de cianogênio, que é um gás extremamente tóxico tornando o método menos viável As características lacrimogêneas do brometo de cianogênio são bastante contornáveis pela utilização de materiais de segurança como máscaras, óculos, luvas e exaustão. Estas características levaram a escolha deste último como agente de cianação (WHITTEN, MACCARTHY, MATTHEWS, 1985, 1986, 1988).

Este processo tem altos rendimentos. São relatados rendimentos de 50 a $78 \%$ na cianação do 1-metilimidazol (16) (Albuquerque, 1995; Whitten, MacCarthy, Mattews, 1985, 1986, 1988). Porém, o rendimento do produto depende da adição imediata do imidazol alquilado na posição 1 no momento da formação do C.A.P., utilizando-se excesso do imidazol. Um exemplo encontrado na literatura revela que a imediata adição de 1-alquilimidazóis pode levar a diferenças de rendimentos de mais de $50 \%$ na obtenção do composto cianado, quando comparado à adição após certo tempo da formação do C.A.P. (WHITTEN, MACCARTHY, MATTHEWS, 1985, 1986, 1988). 


\subsection{CICLIZAÇÃO}

A funcionalização do 1-metilimidazol (16) pelo grupo ciano na posição 2 obtido na etapa anterior constitui a chave para a etapa da ciclização. É através do grupo ciano que a tiosemicarbazida, na presença de ácido trifluoracético, permitirá a formação do anel tiadiazólico, substituído pelo grupo amino na posição 2' (ALBUQUERQUE, 1995).

Admite-se que em meio fortemente ácido o grupo ciano tenda a ser protonado, como se observa em A, na figura 14 (ALBUQUERQUE, 1995). Após a protonação desse grupamento, a carga positiva adquirida é transferida para o átomo de carbono, conforme a estrutura B. B é atacado pelo grupo amino da tiosemicarbazida gerando o íon $\mathrm{C}$ que desencadeia o processo da ciclização. Visando uma maior estabilização da estrutura formada e também a distribuição da carga residual presente, uma série de equilíbrios tautoméricos se estabelece $(\mathrm{C}, \mathrm{D}$ e $\mathrm{E})$. $\mathrm{O}$ intermediário $\mathrm{E}$ proporciona o ataque do par eletrônico do átomo de enxofre ao carbono originário do grupo ciano, passando assim para um intermediário cíclico F, porém ainda carregado positivamente. Novamente outro equilíbrio tautomérico se estabelece ( $F$ e $G$ ) ocorrendo à perda do cátion $\mathrm{H}^{+}(\mathrm{H})$. Forma-se, então, a estrutura I. O grupo $\mathrm{NH}_{4}{ }^{+}$é eliminado da estrutura chegando-se assim a completa ciclização e formação do anel tiadiazólico.

A figura a seguir, contém o esquema do mecanismo proposto acima para a constituição do composto ciclizado: 


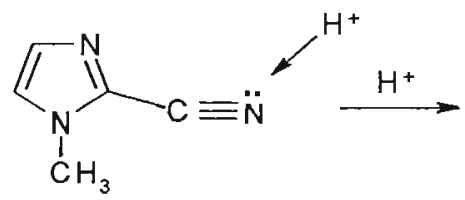

(17)
$\prod_{\substack{\mathrm{N} \\ \mathrm{C} \mathrm{H}_{3}}}^{\mathrm{N}} \mathrm{C} \equiv \stackrel{+}{\mathrm{N}} \mathrm{H}$

(A)<smiles>CC(=N)c1nccn1C</smiles>

$\mathrm{H}_{2} \ddot{\mathrm{N}} \ddot{\mathrm{N}} \ddot{\mathrm{HN}} \mathrm{H}_{2}$

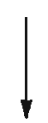<smiles>Cn1ccnc1C(=N)NNC(=S)S</smiles>

(D)<smiles>[Te]</smiles><smiles>Cn1ccnc1C(=[NH2+])NNC(=N)S</smiles>

$(E)$<smiles>Cn1ccnc1C1(N)NN=C(N)S1</smiles>

(H)<smiles>Cn1ccnc1C1([18NH])NN=C(N)S1</smiles>

(I)<smiles>C#CC#CCNC(=N)c1nccn1C</smiles>

(C)<smiles>Cn1ccnc1C1(N)NNC(=N)[SH-]1</smiles><smiles>Cn1ccnc1C1(N)NN[C@@H](N)S1</smiles>

(G)<smiles>Cn1ccnc1-c1nnc(N)s1</smiles>

(18)

Figura 23: Proposição para mecanismo de ciclização. 


\subsection{NITRAÇÃO}

A química dos nitroimidazóis demonstra que a introdução do grupo nitro, preferencialmente na posição 5 , deve ser realizada em meio fortemente ácido e em alta temperatura. A bibliografia indica que vários sistemas nitrantes podem ser empregados (NAGARAJAN et al, 1982). Neste trabalho o sistema nitrante escolhido foi uma mistura de ácido nítrico e ácido acético, que deve ser eficiente para nitrar o produto ciclizado obtido na etapa anterior (REMERS, et al, 1969, 1972)

Neste caso em particular, devido à presença da função amina no intermediário a ser nitrado, é necessária uma proteção deste grupamento. Para tal, emprega-se o método clássico de utilização de anidrido acético, que converte o grupo amino em amida e também libera, como subproduto, ácido acético.

Sabe-se que à medida que o processo de nitração avança, a solução faz-se mais diluída, devido à formação de água durante a reação. A presença do ácido acético garante, não só que o meio continue ácido o suficiente para que o grupo nitro se direcione para a posição 5 , mas também evita que o grupamento acetil protetor seja removido.

Uma vez que o produto nitrado foi obtido, este deverá ser tratado com ácido clorídrico para a conversão da amida em amina 
novamente. Com isso, obtém-se o 1-metil-2-(5-amino-1,3,4tiadiazolil)-5-nitroimidazol, o megazol (12).

A figura 24 mostra as etapas da nitração do 1-metil-2-(5amino-1,3,4-tiadiazolil)-imidazol (18):<smiles>CCCCCCCCCCC</smiles><smiles>CN(C)c1nnc(-c2nccn2C)s1</smiles>

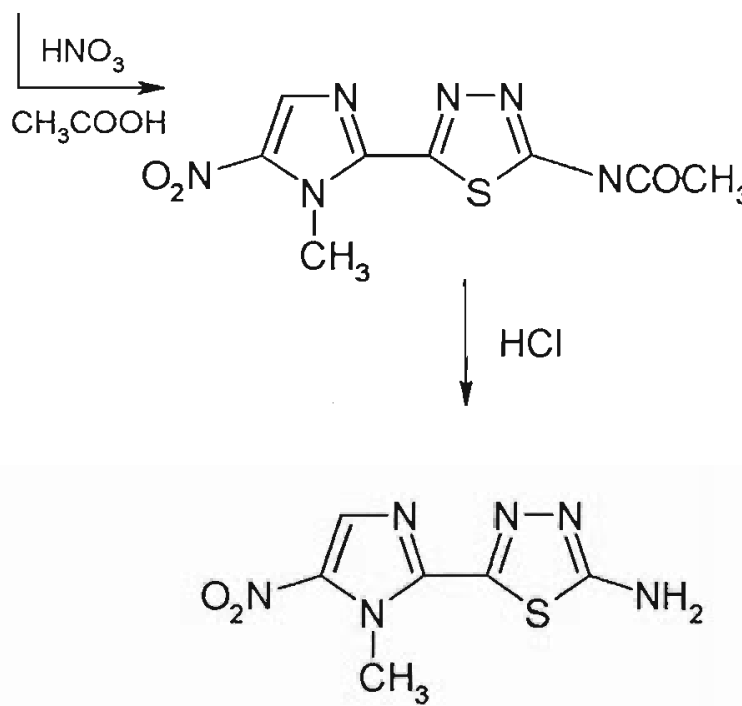

(12)

Figura 24: Esquema da nitração. 


\section{RESULTADOS E DISCUSSÃO}

\subsection{EXECUÇÃO DA CIANAÇÃO}

A cianação via C.A.P. foi bem sucedida desde os primeiros ensaios, sendo a presença do grupo ciano identificada por espectroscopia de ressonância de próton e carbono (ver anexos). Foram realizados repetições com rendimento máximo de $45 \%$. Provavelmente, o baixo rendimento encontrado está relacionado com a proporção entre os reagentes, temperatura de reação e principalmente perdas na etapa de purificação do produto. Um estudo de otimização da cinação do 1-metilimidazol (16) torna-se, portanto, necessário.

\subsection{EXECUÇÃO DA CICLIZAÇÃO}

Nos primeiros ensaios, ocorreram alguns problemas operacionais, como:

a) Eliminação da dimetilformamida da etapa anterior, que reage com o ácido trifluoracético, prejudicando o rendimento da ciclização.

b) Formação de sal ácido, na etapa da neutralização, devido ao pequeno volume de solvente.

Para contorná-los passou-se a eliminar a dimetilformamida através de um tratamento com solução $1 \mathrm{~N}$ de cloreto de amônio, antes da extração do produto cianado. 
No caso da formação do sal ácido efetuou-se uma adição de gelo picado ao meio reacional antes da adição do hidróxido de amônio.

Até o presente momento, um rendimento médio de $26 \%$ foi obtido, ainda abaixo das projeções. Para aumentar esse rendimento serão realizados novos estudos de otimização. Foram feitas análises de ressonância magnética (ver anexos).

\subsection{EXECUÇÃO DA NITRAÇÃO}

A primeira nitração foi reproduzida de acordo com a proposição original. Pela metodologia indicada na bibliografia, o produto da nitração deve ser tratado com água, precipitando assim o composto nitrado, mas ainda na forma de amida. Porém, a adição de água solubilizou-o. Atribui-se esta solubilização a duas hipóteses: a possível baixa quantidade do produto esperado, que desta forma não teria atingido o valor do produto de solubilidade e a salificação do produto. Em vista dessas hipóteses, a solução foi neutralizada com solução de hidróxido de amônio e realizou-se a extração do produto orgânico com acetato de etila. Após a evaporação do solvente seguiuse o método descrito para conversão do grupo amida em amino, com ácido clorídrico concentrado.

O produto sintetizado foi comparado com uma amostra de megazol (12) obtida por outros métodos de sintese, por cromatografia em camada delgada com indicador de fluorescência, revelando não ser o produto esperado. Uma grande parte da amostra não migrou nas 
placas. A parte que migrou não era equivalente ao megazol (12). A repetição do método levou, novamente, aos mesmos resultados.

Novas tentativas foram feitas alterando-se alguns itens nos métodos bibliográficos. Duas tentativas foram realizadas alterando-se a nitração de banho-maria a $100^{\circ} \mathrm{C}$ para temperatura de refluxo. Os produtos gerados foram comparados pelo mesmo método cromatográfico, revelando que a nitração na posição 5 do anel imidazólico levou a uma substância diversa da esperada.

Em vista da possibilidade da formação de um sal, mediu-se o ponto de fusão do produto. A fusão se iniciou em torno de $270^{\circ} \mathrm{C}$ (P.F. do megazol) completando-se em torno de $320^{\circ} \mathrm{C}$, indicando um sal. Logo, supõe-se que há uma mistura de megazol (12) e seu sal. $\mathrm{Na}$ tentativa de dessalificação do produto, a mistura foi dissolvida em água gelada, em banho de gelo e neutralizada com solução de hidróxido de amônio. Os resultados foram os mesmos.

O produto foi, então, neutralizado com solução de hidróxido de amônio e mantido em banho-maria à temperatura de $50^{\circ} \mathrm{C}$ durante 50 minutos. Depois em banho-maria a $60^{\circ} \mathrm{C}$ durante 2 horas. $\mathrm{O}$ tempo do banho-maria foi, então, prolongado para 4 horas e em nenhuma dessas condições foi possível obter o produto esperado.

Nos novos ensaios realizados, considerou-se importante a etapa de precipitação do produto ainda na forma de amida. Seguiu-se o método clássico e após a nitração a mistura reacional foi concentrada. 
Ao invés de água, gelo foi adicionado. Neste caso houve formação de um resíduo sólido. Partiu-se para a etapa de conversão de produto que deveria estar na forma de amida, de acordo com a metodologia indicada na bibliografia. Após a hidrólise da amida com ácido clorídrico concentrado a mistura foi neutralizada com solução saturada de bicarbonato de sódio. O produto foi levado à secura em evaporador rotatório e a fase orgânica foi extraída com tetraidrofurano, no qual o megazol (12) é altamente solúvel. Após a evaporação do solvente foram feitos testes comparativos em placas cromatográficas, frente a padrão. Nos dois ensaios realizados o resultado foi o mesmo. A fase orgânica era composta por um mistura na qual apareceram apenas traços de megazol (12). 


\section{CONCLUSÕES E PERSPECTIVAS}

Até o presente momento pode-se dizer que a rota de síntese proposta para a obtenção do megazol (12) é bastante viável.

A primeira etapa, após algumas alterações operacionais, mostrou um rendimento de $45 \%$, condizente com a literatura, mas necessitando de uma otimização.

A segunda etapa apresentou um rendimento parcial de $26 \%$, necessitando de um estudo de otimização, enfocando-se a metodologia de purificação do intermediário.

A terceira e última etapa foi desenvolvida segundo as indicações da literatura, chegando-se a obtenção de traços de megazol (12) o que leva a considerar a eficiência do método proposto e justifica um posterior estudo visando à modificação das condições operacionais, como tempo, temperatura, proporção entre os reagentes, para aumentar o rendimento dessa etapa.

Portanto, conclui-se que a rota proposta é adequada à obtenção do megazol (12) necessitando de uma complementação teórica e experimental. 


\section{BIBLIOGRAFIA}

ALBRIGHT, J.D., SHEPHERD, R.G. Reactions of 1,2-dimethyl-5nitroimidazole, novel methods of conversion of the 2-methyl group to a nitrile. J. Hetercycl. Chem., Provo, v.10, p. 899-907, 1973.

ALBUQUERQUE, C.N. Synthèse et études physicochimique d' analogues du Megazol, antiparasitaire du type nitro-imidazole; études de leur mode d'action. Toulouse, 207 p., 1995. (Tese de Doutoramento, Université Paul Sabatier, França).

ANDRADE, S.G., MAGALHAES, J.B., PONTES, A.L. Evaluation of chemotherapy whit benznidazole and nifurtimox in mice infected with Trypanosoma cruzi strains of different types. Bull. WHO, Geneva, v.63, n.4, p. 721-6, 1985.

BERKELHAMMER, G., ASATO, G. 2- amino - 5(1-methyl-5-nitro2-imidazolyl)-1,3,4-thiadiazole: a new antimicrobial agent. Science, Washington, v.162, p. 1146, 1968.

BRECCIA, A., CAVAllERI, B., ADAMS, G. E. Nitroimidazoles: chemistry, pharmacology and clinical application. London, 201 p., 1982.

BRENER, Z. Present status of chemotherapy and chemophophylaxis of human trypanosomiasis in the western hemisphere. Pharmacol. Ther., Oxford, v.7, p. 71-90, 1979. 
BRENER Z., ANDRADE, Z. A., BARRAL-NETTO, M. Terapêutica experimental da doença de Chagas. p. 379-386, 2000.

BURDEN, E.J., RACETTE, E. 2-amino-5-(1-methyl-5-nitro-2imidazolyl)-1,3,4-thiadiazole, a new antimicrobial agente. IX. Action against hemoflagellate infections in laboratory animals. Antimicrob. Agents Chemother., Washington, v.7, p. 545-7, 1968.

CRUZ, F.S., VILLALTA, F., MUNIZ, R.F.A. Mechanism of nifurtimox toxicity in different forms of Trypanosoma cruzi. Biochem. Pharmacol., London, v.30, n.14, p. 1947-51, 1981.

DAVIES, D. T. Aromatic heterocyclic chemistry. Oxford, p. 20-27, 1992.

DE CASTRO, S.L. The challenge of Chagas'Disease chemotherary: an update of drugs assayed against Trypanosoma cruzi. Acta Tropica, Basel, v.53, p. 83-98, 1993.

DIAS, J. C. P., JATENE, A. D. Doença de Chagas no Brasil - Situação atual e perspectivas. Ver. Soc. Bras. Med. Tropical, Rio de Janeiro, v.35, supl.3, p.6-8, 1992.

DO CAMPO, R., MARR, J. J. Chemotherapy of Chagas'disease: a perspective of current therapy and considerations for future research. Rev. Infec. Dis., Chicago, v.8, n.6, p.884, 1986. 
FILARD, L.S. BRENER, Z. A nitroimidazole-thiadiazole derivative with curative action in experimental Trypanosoma cruzi infections. Ann. Trop. Med. Parasitol., Liverpool, v.76, p. 293-7, 1982.

CHAUVIÈRE, G., BOUTEILlE, B., ENANGA, B., ALBUQUERQUE, C. N., CROFT, S. L., DUMAS, M., PERIÉ, J. Synthesis and biological activity of nitro heterocycles analogous to megazol, a trypanocidal lead. J. med. Chem., Toulouse, v.46, p. 42740, 2003.

GILCHRIST, T. L. Heterocyclic chemistry. Cambridge, p. 86-195, 1985.

JACOB, M., Régnier, G.L., Crisan, C., U.S. Patent 2,944,061, July, 1960 Chem. Abstr., p. 1657, 1961.

JOULE, J. A., MILL, K., SMITH, G. F. Heterocyclic chemistry. USA, p. 366-88, New York, 1995.

JOULE, J. A., SMITH, G. F. Heterocyclic chemistry. New York, p. 299-320, 1978.

NAIR, M. D., NAGARAJAN, K. Nitroimidazoles as chemotherapeutic agent. Prog. Drug Res., Bombayl, v.27, p. 163-252, 1983. 
NAGARAJAN et al, Nitroimidazoles: Part IV - 1-Sulphonyl (carbamoyl/thiocarbamoyl)-3-(1-methyl-5-nitroimidazol-2-yl)-2imidazolidinones. Indian Journal of Chemistry, Bombay, v.21B, p. 928-39, 1982.

MEO, M., VANELlE, P., BERNADINI, E., LAGET, M., MALDONADO, J., JENTZER, O., CROZET, M.P. DUMÉNIL, G. Evaluation of the mutagenic and genotoxic activities of 48 nitroimidazoles and related imidazole derivatives by the AMES test and the SOS chromotest. Environ. Mol. Mutagen., New York, v.19, p. 167-81, 1992.

MORETTO, S.A.G. Otimização da Rota de Síntese do Megazol, Potencial Antichagásico, [Dissertação de Mestrado], 89 p., Universidade de São Paulo, 2001.

POZHARSKII, A. F., SOLDATENKOV, A. T., KATRITZKY, A. R. Heterocycles in life and society. London, 268 p., 1997.

REMERS, W.A., GIBS, G.J., WEISS, M.J. Preparation of halomethyl1,3,4-thiadiazole, conversion to 2-amino-5-(1-methyl-5-nitro-2imidazolyl)-1,3,4- thiadiazole, an important antimicrobial agent. $J$. Heterocycl. Chem., Provo, v.6, p. 835-40, 1969.

REMERS et al. U.S. Patent, 3,700,684, Chem. Abstr., Oct. 1972. 
TSUHAKO, M.H., ALVES, M.J.J., COLLI, W., BRENER, Z., AUGUSTO, O. Restricted bioreductive metabolism of a nitroimidazole-thiadiazole derivative with curative action in experimental Trypanosoma cruzi infections. Biochem. Pharmacol. London, v.38, p. 4491-6, 1989.

TSUHAKO, M.H. Metabolismo redutivo dos tripanocidas: megazol e nifurtimox. São Paulo, 1990. 84p. (Dissertação de mestrado, Universidade de São Paulo).

WHITTEN, J.P., MACCARTHY, J.R., MATTHEWS, D.P. N-CyanoN'Alquilimidazolium ylids as novel intermediates to 2cyanoimidazoles. Tetrahedron Letters, Indiana, v.26, n.51, p. 6273-6, 1985.

WHITTEN, J.P., MATTHEWS, D.P., MACCARTHY, J.R. [2(trimethylsilyl)ethoxi]methyl (SEM) as a novel and effective imidazole and fused aromatic imidazole protecting group. J. Org. Chem., Baltimore, v.51, p. 1891-2, 1986.

WHITTEN, J.P., MACCARTHY, J.R., MATTHEWS, D.P. Cyanogen Bromide-Dimethylaminopyridine (C.A.P.): A Convenient Source of Positive Cyanide for the Synthesis of 2-Cyanoimidazoles. Communications, USA, p. 470-2, 1988. 
WINKELMANN, E., RAETHER, W., GREBERT, V., SINHARAY, A. Chemotherapeutically active nitro compounds. 5-nitroimidazoles (part I). Arzneim. Forsch./Drug Res., Basel, v.12, p. 2251-63, 1977.

YOUNG, D. W. Química de los heterociclos. Madri, 185 p., 1978. 


\section{ANEXOS (ESPECTROS)}
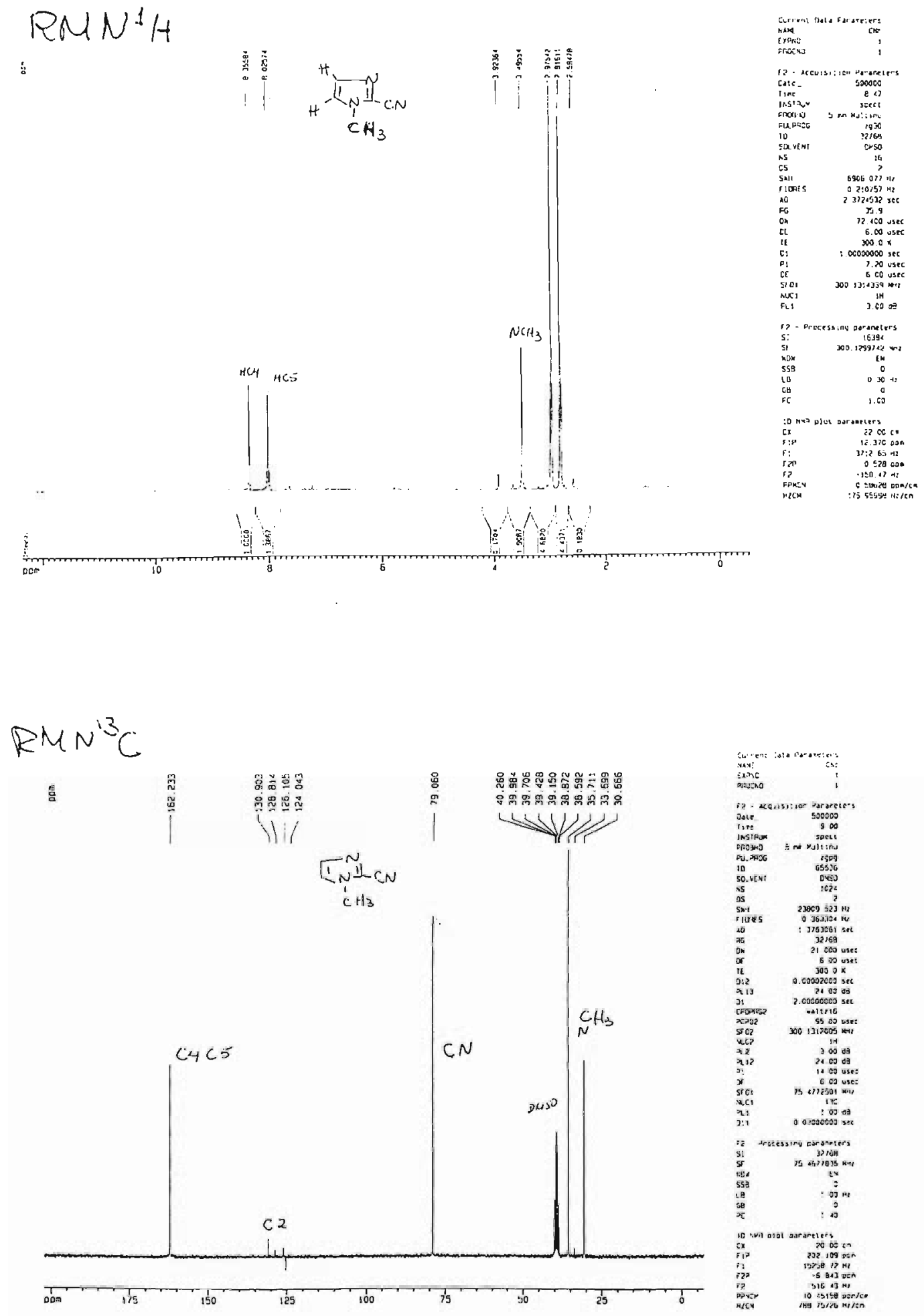

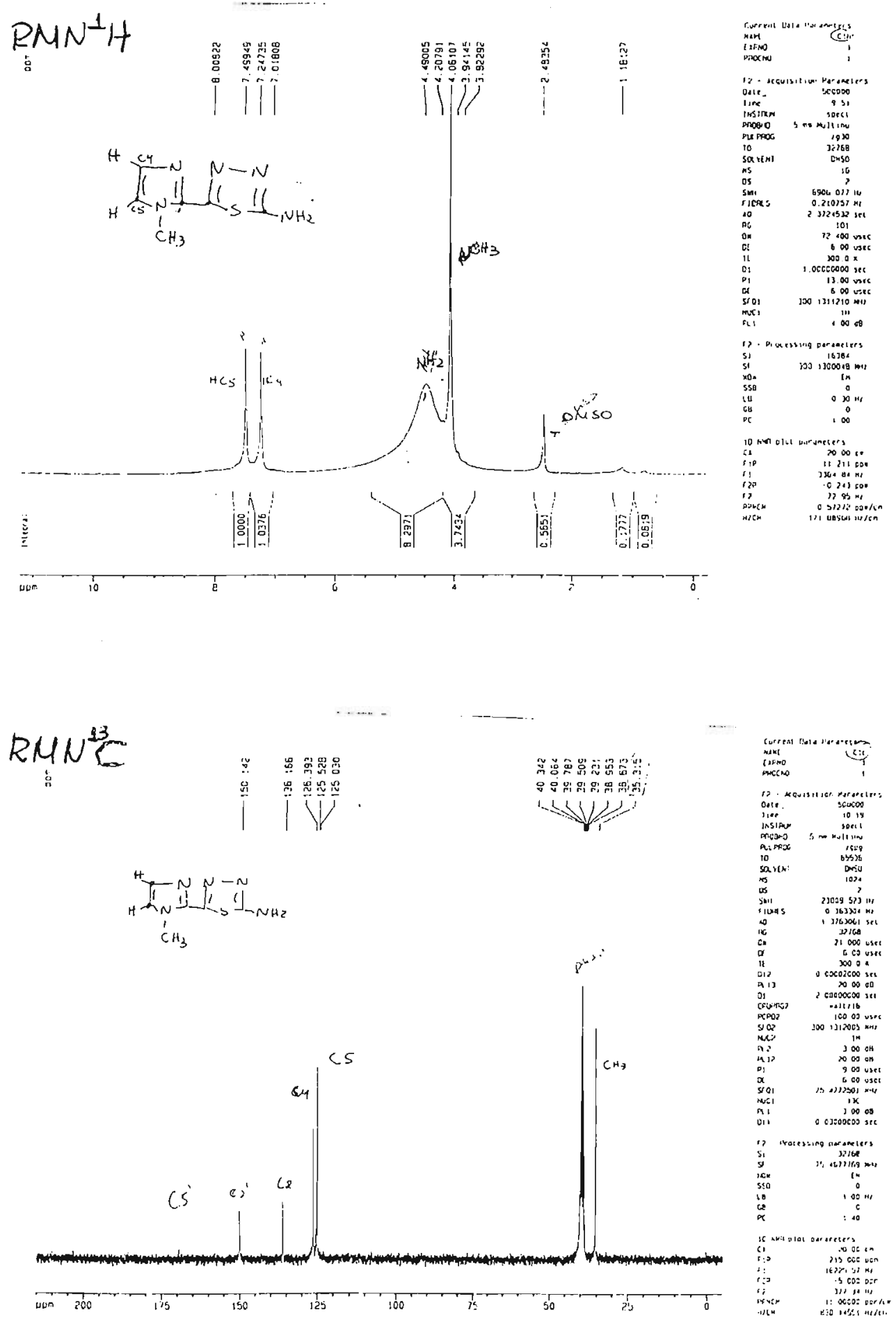